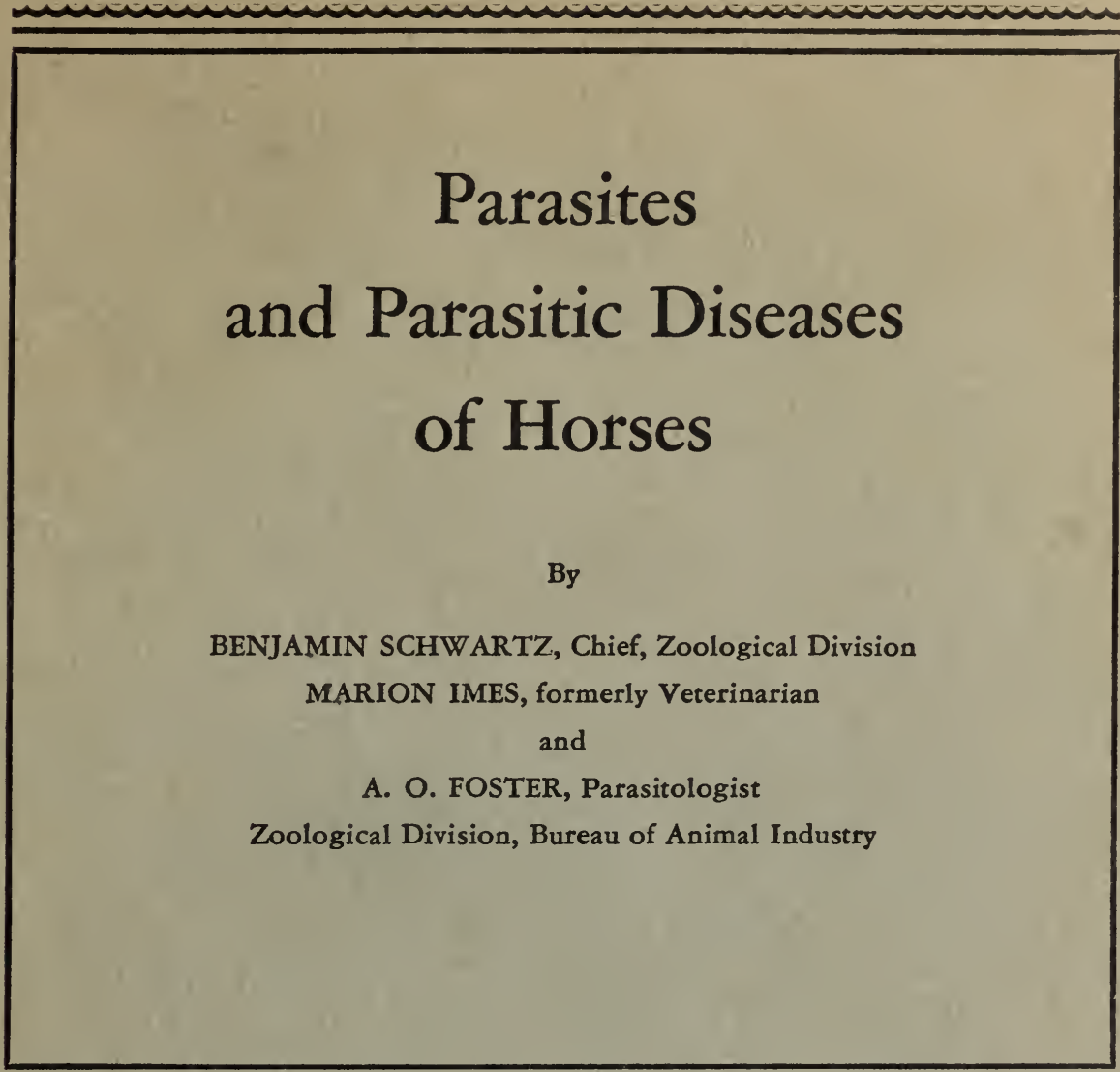

\title{
and Parasitic Diseases
}

\section{of Horses}

For sale by the Superintendent of Documents, Washington 25, D. C. . . . . - Price 20 cents

\section{UNITED STATES DEPARTMENT OF AGRICULTURE}

\author{
WASHINGTON, D. C.
}

Issued November 1930; revised July 1948
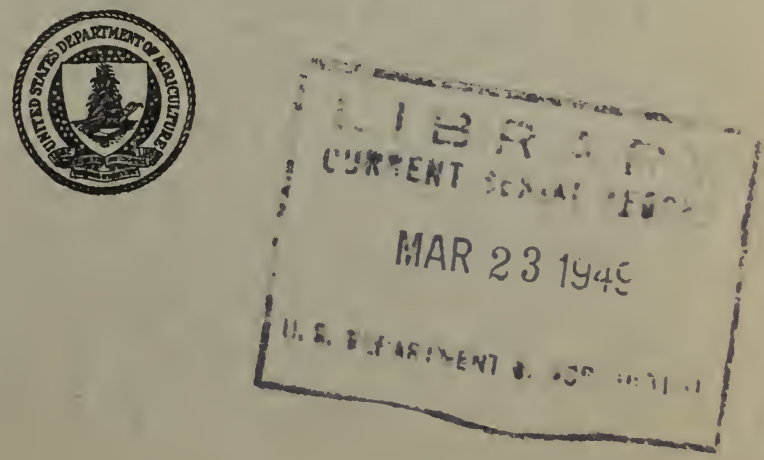



\section{Historic, archived document}

Do not assume content reflects current scientific knowledge, policies, or practices. 



\section{Parasites and Parasitic Diseases of Horses ${ }^{1}$}

By Benjamin Schwartz, Chief, 7oological Division, Marion Imes, formerly Teterinarian, and A. O. Foster, Parasitologist, \%oological Division, Bureau of Animal Industry

\section{CONTENTS}

\begin{tabular}{|c|c|c|c|}
\hline \multicolumn{2}{|c|}{ Page } & \multicolumn{2}{|l|}{. Page } \\
\hline Internal parasites of horses _..... & 1 & Internal parasites of horses-Con. & \\
\hline Abundance and location & 1 & Disposal of manure & 34 \\
\hline Symptoms and damage pro- & & Summary of control measures & 36 \\
\hline duced by parasites & 2 & External parasites of horses & 37 \\
\hline General control measures..... & 2 & Horse lice $\ldots \ldots$ & 37 \\
\hline Medicinal treatment & 3 & Horse mange $\ldots \ldots \ldots$ & 42 \\
\hline Protozoa $\ldots \ldots \ldots \ldots \ldots$ & 4 & Ticks _. & 48 \\
\hline Worm parasites _....... & 4 & Treating horses for external & \\
\hline Bots & 32 & parasites _............... & 52 \\
\hline
\end{tabular}

\section{INTERNAL PARASITES OF HORSES ${ }^{2}$}

\section{Abundance and Location}

THE TERM PARASITE as used in this circular refers to forms 1 of animal life which, ror the purpose of obtaining food and shelter, live on or in the bodies of other animals which are larger than the parasites and are known as hosts. All classes of domesticated animals harbor numerous kinds of parasites, and horses, in particular, are liable to infestation not only with many different kinds but also with very large numbers of injurious species. A horse's stomach may contain hundreds of bots, and the small intestine may be packed with large roundworms. The large intestine of the horse is a location especially preferred by parasites, and very often the colon and cecum are found to be teeming with hundreds or thousands of wriggling, parasitic worms, some free in the lumen and others attached to the walls of the gut. Several kinds of worm parasites present in the gut and elsewhere have previously wandered through various parts of the

\footnotetext{
1 This circular supersedes Farmers' Bulletin No. 1493, Lice, Mange, and Ticks of Horses.

2 By Benjamin Schwartz and A. O. Foster. Dr. Foster has revised most of the section originally prepared by Dr. Willard H. Wright. Many of the illustrations in this section of the circular were drawn by Joseph E. Alicata, formerly junior zoologist.
} 
horse's body before reaching their final locations. In fact, there is hardly an organ or a tissue in the horse which is absolutely free from possible attacks by mature parasites or by their wandering larval forms.

\section{Symptoms and Damage Produced by Parasites}

Parasitic diseases, unlike diseases caused by bacteria, are seldom spectacular in their onset and symptoms and are marked by a slowly progressing chain of symptoms which the owner may entirely overlook or confuse with other conditions. The general symptoms of worm intestation in the horse are unthriftiness, weakness, emaciation, tucked-up flanks, distended abdomen, rough coat, whitening or bleaching of the mucous membranes (noticed particularly in the mucous lining of the eyelids and mouth), and in some cases frequent colics and diarrhea. The appetite usually remains good and the animal shows no rise in temperature. Heavily parasitized animals tire quickly and are frequently unable to stand heavy work.

Parasites are particularly damaging to young, growing animals. They attack the foal when it should be making its best growth and produce stunting and lack of development. A considerable part of this damage is a result, no doubt, of the wanderings of the larval worms through various parts of the body of the host before they reach their preferred location where they develop to maturity.

While the death rate from parasitic infestation is not high, nevertheless these internal pests cause considerable damage. The loss is represented largely by the poor development and stunting of foals, inability of heavily parasitized horses to do a normal amount of work, added costs of feed and maintenance, and loss of working time from verminous colics. There is evidence also that the countless small wounds that are caused by some parasites may serve as portals of entry for disease-producing organisms such as bacteria, and that heavily parasitized equines may already have a lowered resistance to disease.

\section{General Control Measures}

Most internal parasites of livestock owe their perpetuation to the fact that domestic animals often take their food from the same places they deposit their fecal matter. The eggs of parasites are passed by horses with the manure in stables and on pastures and then go through various stages of development, after which either the eggs or the larval worms reach the interior of the horse with the food and drinking water. Prevention must be directed toward breaking this cycle. Stables and paddocks should be kept in a sanitary condition by the frequent removal of manure. Concrete standings, although objected to by some horsemen, have the advantage of being easily cleaned and provide a relatively unfavorable medium for the development of parasites. If wooden standings are used, the timber should be sound. Rotten, moisture-soaked floors are difficult to keep clean, and they provide a favorable medium for the development of parasites. If standings of earth are used, it is advisable to remove the top layer of soil down to 10 or 12 inches once or twice a year and replace it with clean, uncontaminated soil. 
Horses should be fed grain from feed boxes and hay from racks which are sufficiently high above the ground or the floor of the stall to prevent contamination of the feed with manure. Watering troughs should be so constructed as to prevent similar contamination of the drinking water. Horses should not be forced to obtain drinking water from pasture or barnyard pools. In general, low, wet pastures are more favorable for the propagation of parasites than are high, well-drained areas. Animals grazed on heavily stocked, permanent pastures have greater opportunity for picking up parasite eggs and larvae than those changed frequently from one pasture to another. For this reason pastures should be changed as often as possible. The common practice of spreading horse manure on pasture plots adds to the parasite burden of the pastures. Suitable treatment of manure before spreading, as described in this circular, will prevent this added contamination.

\section{Medicinal Treatment}

It is not always practicable on the average farm to apply the sanitary measures necessary for the prevention of parasitic infestation in horses. Treatment is, therefore, an important consideration. Periodic treatment will not only reduce infestation in parasitized horses and render the animals more serviceable but will likewise reduce the output of eggs in the manure, with a resultant decrease in stable and pasture contamination.

Prevention of parasites in horses by the application of sanitary measures is the business of the horse owner, but the diagnosis and treatment of parasitic diseases are functions of the veterinarian. Different parasites require different and more or less specific treatments. Before these treatments can be intelligently applied it is necessary to know which species of parasites are present. The veterinarian is qualified by training and experience to ascertain this.

Drugs used in treatments for horse parasites should be administered, as a rule, in capsules or by stomach tube, the latter being the preferred method for certain drugs. If capsules containing an irritant or volatile drug are broken in the mouth, some of the drug may be drawn into the windpipe and cause serious consequences. All drugs used in the treatment of horse parasites are poisonous, being intended to poison the parasites, and great care must be used in selecting the dose in accordance with the weight and condition of the animal. Some drugs should not be used in the presence of certain conditions and, if used under such unfavorable circumstances, may cause serious results. Because treatment involves diagnosis and an intimate knowledge of how a drug acts and when to use it or not to use it, it is advisable that all treatments for horse parasites be administered by a veterinarian.

The treatments recommended in this circular are, for the most part, those which have been found by experimentation to be the most effective for the parasite or parasites involved. Many drugs, some of them long purported to be of value for the expulsion of worms from the horse, have been found to be practically worthless for this purpose when critically tested. Among such preparations may be mentioned iron sulfate, arsenic, copper sulfate, and tartar emetic. 
It should be especially noted that some drugs, like oil of chenopodium, require preparatory fasting of the animals and that some other drugs, notably phenothiazine, do not require this regimen. If a preliminary fasting period is necessary, one should not neglect to allow water during this time. Moreover, safe and effective medication with any of the drugs that are used against parasites requires close adherence to the recommended dosages and methods of administration. To keep parasitic infestation at a minimum and avoid losses from this source, it is advisable to adopt a program of regular treatment. The usual procedure is to administer treatments twice a year. In the northern part of the United States, animals may be treated for worm parasites in the late spring or early summer and in the fall. In the South, owing to the shorter and milder winter and the more abundant warmth and moisture, it may be necessary to treat oftener. Judgment, based on experience, is a better basis for procedure than any general rule.

Internal parasites occur in various locations in the body of the host animal, such as the alimentary canal, lungs, liver, kidneys, blood, and various organs and tissues other than the skin. They include various forms of animal life known as Protozoa, worms, the larval forms of certain insects, and some forms closely related to insects. The various kinds are discussed in detail in the following pages.

\section{ProtozoA}

Protozoa are relatively low forms of animal life, microscopic in size, and consisting of but a single cell. The parasitic protozoa of domesticated animals are known to occur in various locations, and are especially common in the alimentary canal and in the blood. Fortunately, horses in the United States are relatively free from certain disease-producing protozoan parasites which occur in horses in other parts of the world where they constitute a limiting factor in horse production. The only known pathogenic protozoan parasite of horses in this country is the organism, one of the trypanosomes, which produces dourine. ${ }^{3}$ Trypanosomes closely related to this organism occur in the blood of horses in South America, Asia, the Philippine Islands, and elsewhere, and produce serious and fatal diseases. Up to the present time these parasites have not become established in this country, and quarantine measures to keep them out are enforced.

Protozoan parasites of various kinds often occur in large numbers in the cecum and the upper colon of horses, but these forms are not definitely known to produce any digestive or other disturbances and are usually regarded as comparatively harmless.

\section{Worm Parasites}

The worm parasites of horses are flukes, tapeworms, and roundworms, the last-mentioned group being the most common and injurious.

\footnotetext{
${ }^{3}$ Information concerning dourine is published in Farmers' Bulletin 1146, Dourine of Horses.
} 


\section{FLUKES}

Flukes or trematodes are soft, more or less flattened, leaf-shaped worms, occurring in various locations, especially in the digestive tract and in organs which communicate with the digestive tract. Only a few kinds of flukes are known to occur in horses, and several of the forms which have been reported from these animals normally occur in other hosts and are only accidental parasites of the horse. The only fluke likely to be encountered in horses in this country is the common liver fluke of cattle and sheep, which is occasionally found in the horse. Horses on the west coast, in the South, and in the Southwest are likely to become infested with liver flukes, especially if they have access to pastures on which fluky sheep and cattle have grazed. Liver flukes occur in the bile ducts of the liver and produce a serious disease, especially in sheep. The larval forms of flukes require snails as intermediate hosts and occur only on pastures sufficiently wet to favor certain kinds of snails.

Liver-fluke disease in horses has not been extensively studied, because it is relatively rare in these animals. Prevention consists in keeping horses off low and swampy pastures, and these precautions should be especially observed in those parts of the United States where liver flukes are known to occur. Such pastures favor parasites in general. Farmers' Bulletin 1330 gives information on fluke control.

Treatment.-There is no established treatment for liver-fluke infestation in the horse. However, carbon tetrachloride in small doses has a specific action on the common liver fluke of sheep and is widely used as a treatment for fluke infestation in these animals. Carbon tetrachloride may be given with safety to adult horses in doses of from 6 to 12 fluid drams (25 to 50 cubic centimeters) and in these doses should be effective for the destruction of the flukes.

\section{TAPEWORMS}

A tapeworm is an elongated flattened worm consisting of a head and a chain of segments. Each mature segment contains both male and female organs. The head is provided with four suckers used to attach itself to the wall of the gut. The segments of these tapeworms are considerably wider than long and those which are farthest from the head are the ones which contain eggs. These ripe or gravid segments become detached from the rest of the chain and are expelled from the body with the droppings. Beyond this point nothing is known as regards the further development of horse tapeworms but in view of recent information on related species in ruminants it seems possible that pasture mites may serve as intermediate hosts. There are claims that this view has been experimentally confirmed.

Horses are known to harbor three species of tapeworms, as follows:

The large horse tapeworm, Anoplocephala magna (fig. 1), usually is from $3 \frac{1}{2}$ to 10 inches long. The head is about two-fifths of an inch in width and bears four prominent suckers. With the exception of those immediately adjoining the head, the segments are considerably wider than the head. This parasite occurs in the small intestine and occasionally also in the stomach. 
The dwarf tapeworm of horses, Anoplocephala mamillana (fig. 2), is only from about one-fourth of an inch to 2 inches long and from one-sixth to one-fourth of an inch wide; the head of this worm is rery minute and is barely risible to the naked exe. This tapeworm occurs in the small intestine and is occasionally found in the stomach.

A third species of tapeworm. intermediate in size between the large tapeworm and the dwarf tapeworm. is known as the perfoliate tapeworm. Anoplocephala perfoliata. It is usually from about three-fifths of an inch to over 3 inches long. It occurs usually in the cecum and lower portion of the small intestine. The parasites often become localized in a small area surrounding the opening of the

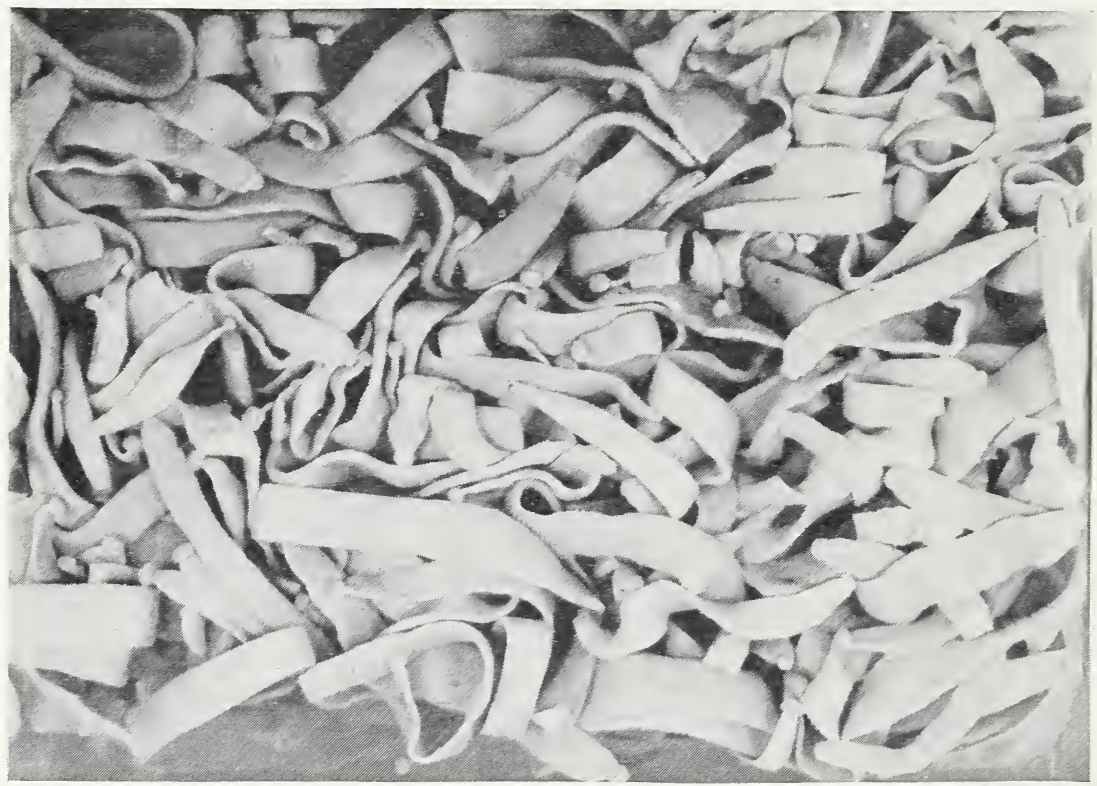

Figure 1.-Almost a gallon of large tapeworms, Anoplocephala magna, removed postmortem from a horse. About one-half natural size. (Photograph by courtesy of the Agricultural and Mechanical College of Texas.)

small intestine into the cecum, the so-called ileocecal ralre region, where ther produce irritative and inflammatory changes, as well as a rapidly growing mass of tissue which progressirely obstructs the opening of the intestine. This species is fortunately much less common in American horses than the other two species of tapeworms.

Symptoms and lesions.- In light infestations no symptoms are present. Horses which are hearily infested with tapeworms may suffer from intestinal catarrh, show digestive disturbances of rarious sorts, and in cases of rery serere infestations they may become emaciated and anemic. The perfoliate tapeworm of the horse often occurs in large numbers when present at all, and is said to produce inflammation of the intestines; sometimes it ruptures the wall of the cecum. The attachment of tapeworms of this species 
to the wall of the cecum produces small ulcers in the regions to which the worms are attached.

Treatment.-Very little is known regarding treatment for tapeworms in the horse. The following treatments have been recommended but have not had critical test to determine their precise value.

Oil of turnentine is said to be an effective remedy. This is given in a dose of 2 fluid ounces (60 cubic centimeters) in capsules, followed every second day by 1 ounce $(30$ cubic centimeters) in capsule until five or six doses have been given. The last dose is immediately preceded or followed by 1 quart of raw linseed oil.

It would seem that the drugs used for the treatment of tapeworm infestation in other animals would offer more promise.

Areca nut may be of value for the removal of tapeworms from the horse. Areca nut, freshly ground, may be given to adult horses in doses of from 1 to 1.5 ounces (30 to 45 grams) in capsules after fasting the animals for 24 to 36 hours. The drug has a purgative action, but if the bowels do not move within 4 or 5 hours, it is advisable to administer 1 to 2 pints of raw linseed oil. Areca nut should not be given to very old or very young animals or to those in a weakened condition.

Kamala may be found to be of value for the removal of horse tapeworms. Kamala may be given to adult horses in doses of 1 ounce (30 grams) in capsule, after they are fasted from 24 to 36 hours. The drug itself has a purgative action and seldom needs to be followed by a purgative. Kamala should not be given to very young or very old animals, to those in a weakened condition, or to those suffering from febrile diseases, such as influenza, distemper (strangles), and infectious anemia (swamp fever).

Oleoresin of male fern is another drug which may be of value for the expulsion of tapeworms from the horse. This drug may be given to adult horses in doses of 3 to 6 drams (10 to 20 grams) in capsules after fasting the animal for 24 hours. The drug should be immediately preceded or followed by 1 quart of raw linseed oil.

The foregoing drugs should be used with caution and given only to animals in good condition and presumably able to withstand any poisonous effects of the drugs.

Prevention.-No definite control measures can be recommended. It should be remembered, however, that the eggs present in gravid segments which are eliminated with the manure are the starting points of new infestations. Any measures which are taken with reference to the proper disposal of manure will aid in preventing infestation with these parasites, especially if the manure is stored and permitted to undergo self sterilization by heating, so far as the destruction of parasite eggs and larvae is concerned. This procedure is described later in this circular.

\section{ROUNDWORMS}

Roundworms or threadworms comprise the vast majority of parasites which infest horses. These worms, which are also known as nematodes, are elongated, cylindrical in shape, and usually tapering at both ends. Some roundworms are almost white, some are grayish white, most of them are yellowish in color, and some are pinkish or 
blood red. Roundworms occurring in the horse have a considerable range of size, the large, intestinal roundworm or ascarid being from 6 inches to over a foot long, while the small stomach worm is only about one-fifth of an inch long. Roundworms reproduce by means of eggs which are produced by the female worms. The eggs are usually eliminated from the horse's body with the manure. Some species of roundworms must be taken up by an intermediate host in which they undergo part of their development, while other species are transmitted from one animal to another directly by eggs or by

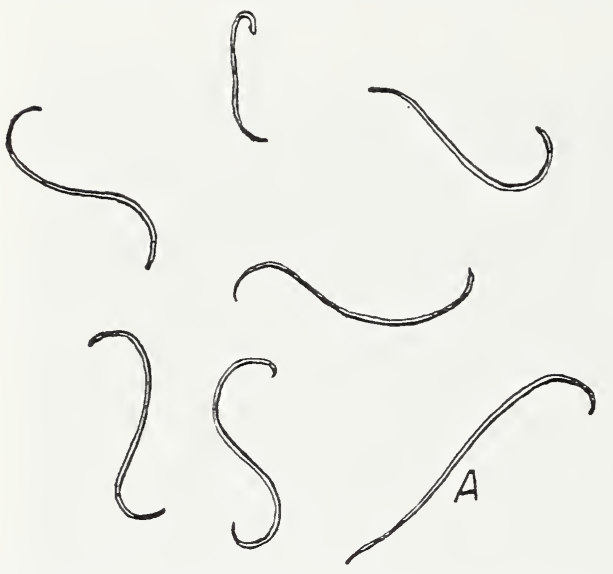

Figure 3.-Large stomach worms of the horse. A. Habronema microstoma; others, H. muscae. Natural size.

one species. The small stomach worm is acquired by horses directly as the result of swallowing infective larvae which occur on pastures. The larvae may also be taken in by horses with water and with dry feed.

THE LARGE STOMACH WORMS

The large stomach worms (fig. 3) are relatively long and slender, are whitish in color, and occur either free in the stomach, embedded in mucus, attached to the wall of the stomach, or in tumors of the stomach wall, for which tumors these worms are responsible.

One species, Carter's stomach worm, Habronema muscae, of the horse, is from about one-third inch to nearly an inch long. This parasite occurs free in the stomach or attached to the wall of the stomach. A second species, the small-mouthed stomach worm, H. majus, synonym $H$. microstoma, is similar in size and appearance to the above species. While this form may occur free in the stomach, it is capable of penetrating its wall and causing sores. A third species, the largemouthed stomach worm, H. megastoma (=Draschia megastoma), of the horse is the smallest of the three species, ranging in length from less than one-third of an inch to about one-half inch. These worms occur in tumors found in the wall of the stomach; the tumors may become very large, attaining the size of a fist or even of a child's head. Usually, however, they are much smaller. 
Life history (fig. 4.).-The eggs of horse stomach worms have very flexible shells; they are deposited in the lumen of the stomach and are eliminated from the horse's body with the feces. When the eggs are swallowed by maggots of house flies, stable flies, or other flies which breed in horse manure, further development takes place which keeps pace with the development of the maggots. 'The larvae of Carter's stomach worm of the horse develop for the most part in house fiies while those of the small-mouthed stomach worms of the horse

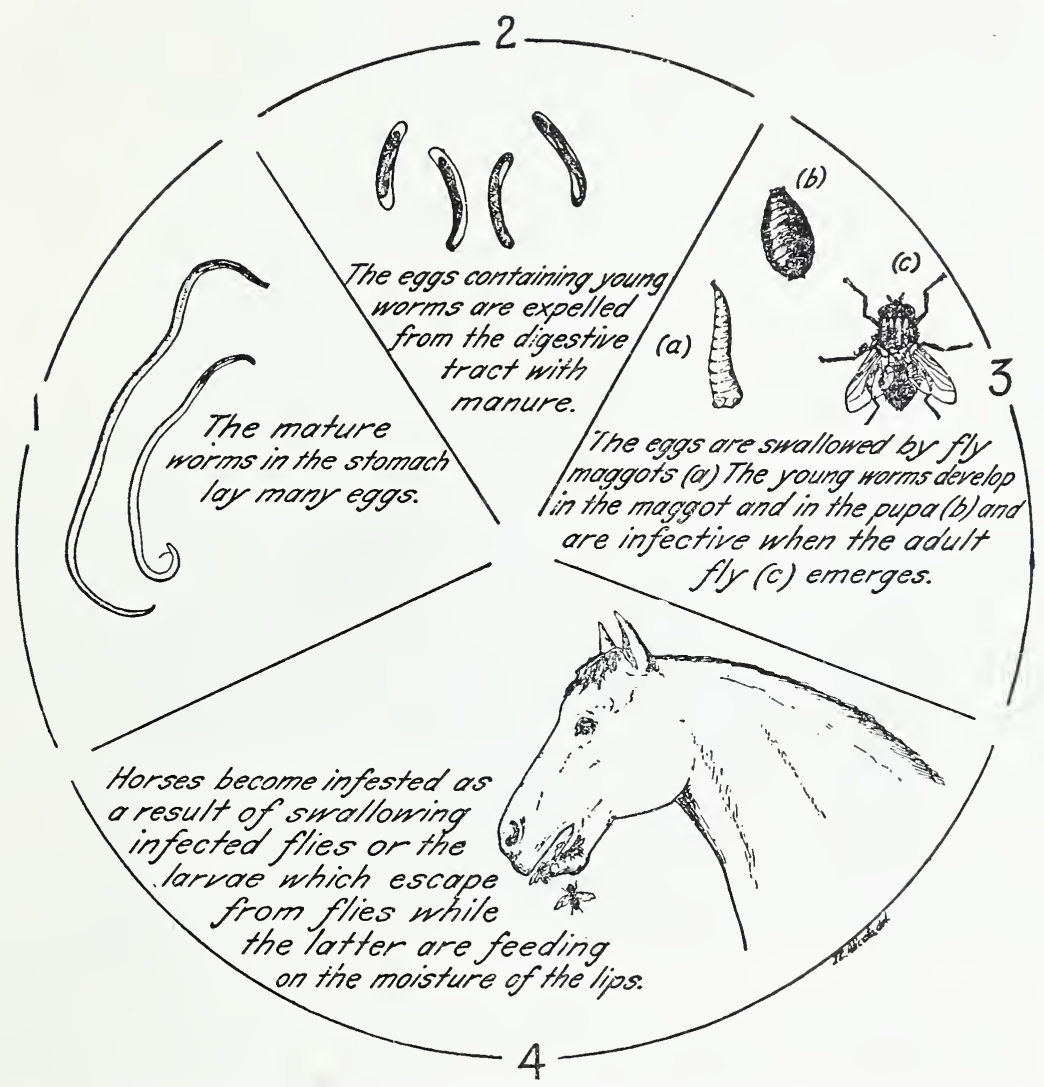

Figure 4.-Life cycle of one of the large stomach worms, Habronema muscae, of the horse. The illustrations of the adult worms are enlarged about 2 times; those of the eggs are enlarged about 150 times.

have stable flies as their usual intermediate hosts, though they are known to develop also in house flies and other flies. The larvae of the large-mouthed stomach worms of the horse develop in various species of nonbiting flies, including house flies. These larvae attain their full growth in the flies when the latter emerge from the pupae. Horses may become infested with stomach worms as a result of swallowing live, infected flies or infected flies which have been dead a short time and still contain the live larval worms. Another and probably more common way in which horses become infected with these parasites is as follows: As the flies suck the moisture of the lips and nose, the 
larvae, which are present in the mouth parts of the insects, escape, the heat and moisture of the horse's body stimulating the larvae to wriggle out of the flies. Once the larvae are on the lips they are readily swallowed. Those larvae which get into the nasal cavities probably wriggle into the pharynx and are also swallowed. When the larvae reach the stomach they are in their normal location where they settle down and develop to maturity. It is possible that the smallmouthed stomach worm is transmitted by the bite of the stable fly.

Symptoms and lesions.-No definite symptoms which indicate the presence of these parasites in the stomach are known. The worms are injurious because of their tendency to attach themselves to and to penetrate into the stomach wall and, in the case of the large-mouthed stomach worm, because of the tumors which they produce. The tumors interfere to a considerable extent with the proper functioning of the stomach. When large tumors are situated near the junction of the stomach and intestine they interfere mechanically with the passage of food. The most evident injury occasioned by the large stomach worms is produced by the larvae which get into the skin of horses where they are commonly associated with a skin disease known as summer sores.

Treatment.-A high degree of efficacy for the destruction of $H$. muscae and $H$. microstoma has been obtained by the use of the following method of treatment. The animal should be fasted for from 18 to 24 hours and the stomach washed out by injecting through a stomach tube 8 to 10 quarts of a 2-percent solution of sodium bicarbonate (baking soda) heated to $105^{\circ} \mathrm{F}$. The solution tends to remove the thick layer of tenacious mucus which normally covers the lining of the stomach and renders the stomach worms more accessible to the action of drugs. It is advisable, though not necessary, to siphon off the sodium bicarbonate solution. If the solution is not siphoned off, an interval of 15 to 20 minutes should elapse before further treatment. Carbon disulfide should then be administered in capsule or by stomach tube in a dose of 6 fluid drams (24 cubic centimeters) for a 1,000-pound animal, or at a dose rate of 1.5 fluid drams (6 cubic centimeters) for each 250 pounds of weight. No purgative should be used with this treatment. $H$. megastoma in stomach tumors is not affected by this treatment and is inaccessible to any method of treatment known at present.

Prevention.-Prevention of stomach-worm infestation in horses involves the storage of manure in closed containers, in order to decrease the number of flies which breed in manure, or the application of other control measures designed to prevent flies from breeding. The use of containers for storing manure with a view to destroying eggs and larvae of parasites is discussed subsequently in this circular. The United States Bureau of Entomology and Plant Quarantine has devised a trap designed to destroy fly maggots which breed in manure. The trap is based on the observation that maggots, when fully grown, migrate out of moist manure and if they are permitted to escape through spaces between the boards of an open manure platform raised on posts and set in a concrete basin of water, they are caught in the basin and drowned.

The advent of DD'T and some of the newer insecticides has provided weapons of unusual value for combating flies. The spraying of stalls 
and barns with suitable preparations of these materials offers promise of being the best means of keeping fly populations at a minimum. Sprays having prolonged insecticidal action are obtainable commercially and should be used in accordance with directions accompanying them.

A skin disease of horses, known as summer sores and characterized by pronounced skin lesions, is associated in some parts of the world, including the United States, with the larvae of the large stomach worms of horses. The sores may be as small as a millet seed, but are usually about the size of a pea and may attain a size about an inch in diameter. The sores are covered by a soft, brownish-red, pulpy material with cracks or furrows which are filled with pus. In the midst of the softened mass there are small, rounded granulations which are firm in texture.

This disease has been studied in Europe, Africa, and elsewhere, where it has been noted that its seasonal occurrence corresponds to the prevalence of flies. It is unlikely that the worm larvae invade the unbroken skin, but it appears to be well established that when a horse's skin is broken by some injury and when flies which carry the worm larvae feed on the sores, the larvae escape from the mouth parts of the fly and live for a time in the wounds. These larvae irritate the sore, so that instead of healing as a simple sore it may become a more or less chronic thing which does not heal until after the occurrence of frost in the fall.

Although conditions known as "summer sores" in horses are known to occur in the United States, the disease has not been extensively studied here, and the relation of stomach-worm larvae to summer sores still needs further investigation in this country. Recently the occurrence of the larval worms from summer sores in horses in the United States has been definitely reported.

Treatment for summer sores.-An astringent powder which is said to prevent the extension of the trouble and to aid in healing consists of the following: Plaster of paris, 100 parts; alum, 20 parts; naphthalene, 10 parts; and quinine, 10 parts.

Good results are reported from the use of a caustic paste composed of arsenious oxide, 1 part, and flour, 5 parts. Washing the sores with ether or chloroform and then painting them with collodion has also been recommended. Some veterinarians prefer the use of a 5- to 10percent solution of formalin, applied by means of a cotton pad which is left on the sores for 2 or 3 hours every day.

Prevention.-Skin injuries should be protected from flies by the use of pine-tar oil or other agents to prevent their conversion into summer sores. Flies should be controlled by the use of residual DDT sprays or other preparations of established efficacy.

THE SMALL STOMACH WORM

This parasite, Trichostrongylus axei, occurs in the lining of the stomach, and is likely to be overlooked, as the worms are very slender and only about one-fifth of an inch or less in length.

Life history. - The life history of this parasite has not been definitely ascertained. In a general way its life history is similar to 
that of blood strongyles, described elsewhere in this circular, with respect to the derelopment of the eggs and larrae on pastures. It is also fairly certain that infestation is direct, and results from the swallowing, by horses, of the infective larvae with food or water. Howerer, these worms burrow only into the stomach wall and are not known to wander extensively, as young worms, throughout the body of the horse.

Symptoms and lesions.-These parasites injure the stomach wall. Sometimes the stomach lining shows areas superficially like a ringworm or a mass of small tumor's (fig. 5). In addition to these injuries the parasites contribute to general gross parasitism in horses which

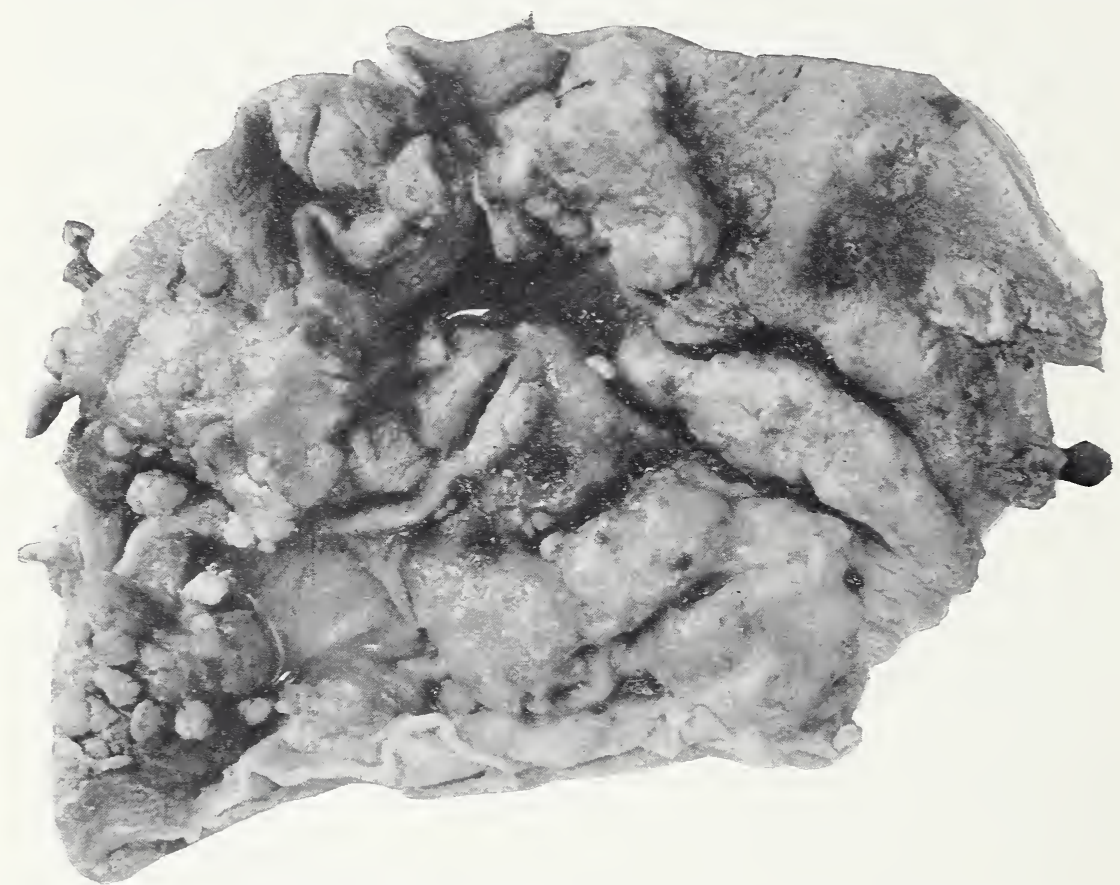

Figure 5.-Portion of the inner lining of a horse's stomach, showing lesions produced by the small stomach worm, Trichostrongylus axei. (Photograph by courtesy of the Agricultural and Mechanical College of Texas.)

is characterized by weakness, paleness of the mucous surfaces, wasting, and digestive disturbances.

Treatment.-It is seldom that specific treatment is employed to remove or destroy these parasites. So far as is known, howerer, the use of phenothiazine, as recommended for removing strongyles, is a reasonably effectire measure. There is some eridence, also, that treatment with carbon disulfide, as described for large stomach worms, may be effective against this species.

Prevention.-Preventive measures are similar in a general way to those discussed in connection with preventive measures against bloodworms and other strongyles. The similarity in control measures is based on similar life hiștories. 
THE LARGE INTESTINAL ROUNDWORMS OR ASCARIDS

The large intestinal roundworms, Parascaris equorum, of horses (fig. 6), also known as ascarids, are cylindrical in shape, yellowish white in appearance, and from about the size of an ordinary lead pencil to about a foot long when fully grown. The head is clearly marked off from the rest of the body and bears three clearly distinguishable lips. Closely related worms occur in pigs, cattle, and human beings. Ascarids occasionally pass out of the bowels spontaneously, in which case they are readily seen, and in horses this is said to take place in the spring of the year.

These worms are located in the upper part, less often in the middle and lower parts, of the small intestine; they are occasionally found in the cecum and in the stomach. They may occur in large numbers, especially in foals and in young horses.

Iife history (fig. 7).-The female worms produce large numbers of eggs which are microscopic in size. The eggs are deposited in the lumen of the horse's intestine and are expelled from the bowels in the manure. Under favorable conditions of temperature and with an adequate supply of moisture, the eggs develop on the ground and on pastures until they reach the infective stage, but the embryos remain in their eggshells until they reach the gut of a susceptible horse. The thick eggshell protects the embryo it contains against various unfavorable influences.

During the summer months the eggs develop to the infective stage in about 2 weels. The low temperatures of cold weather retard the development of the eggs, as does also lack of moisture. Ordinarily sufficient moisture is present in horse manure to favor the development of the eggs. Balls of manure which appear dry on the surface commonly contain sufficient moisture in the middle to permit the normal development of these eggs. Excessive drying destroys the vitality of ascarid eggs.

If infective ascarid eggs are swallowed by horses with grass, water, or dry feed which has become contaminated with horse manure, the embryos are liberated from their shells in the horse's intestine and then burrow into the wall of the gut and migrate with the blood stream to the liver. From this organ they proceed in the blood stream through the

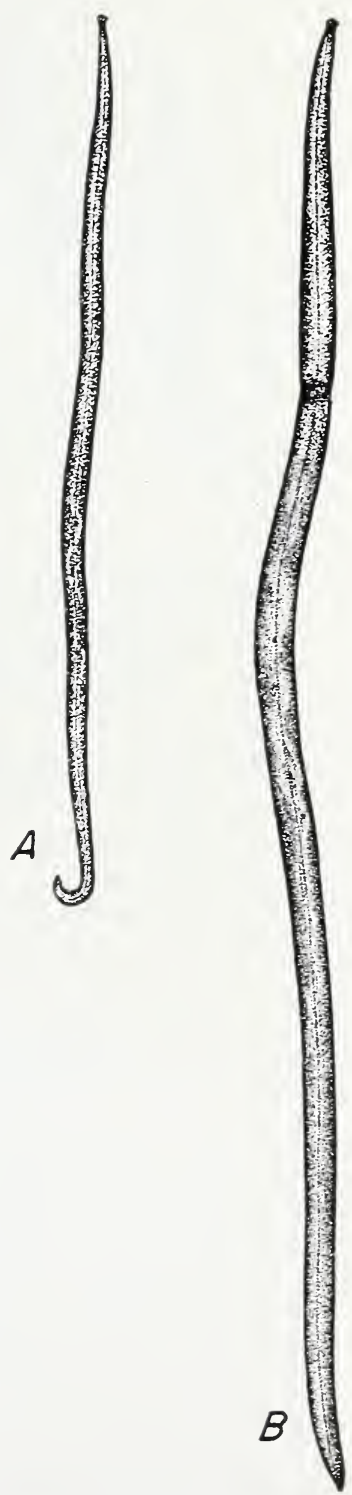

Figure 6.-The large roundworm, Parascaris equorum: A, male; $\mathrm{B}$, female. About one-half natural size. 
heart to the lungs. If many worms go through the lungs at the same time they injure this organ and may produce pneumonia. This roundabout journey from the intestine to the liver and thence to the lungs is completed in about a week. From the lungs, the larvae
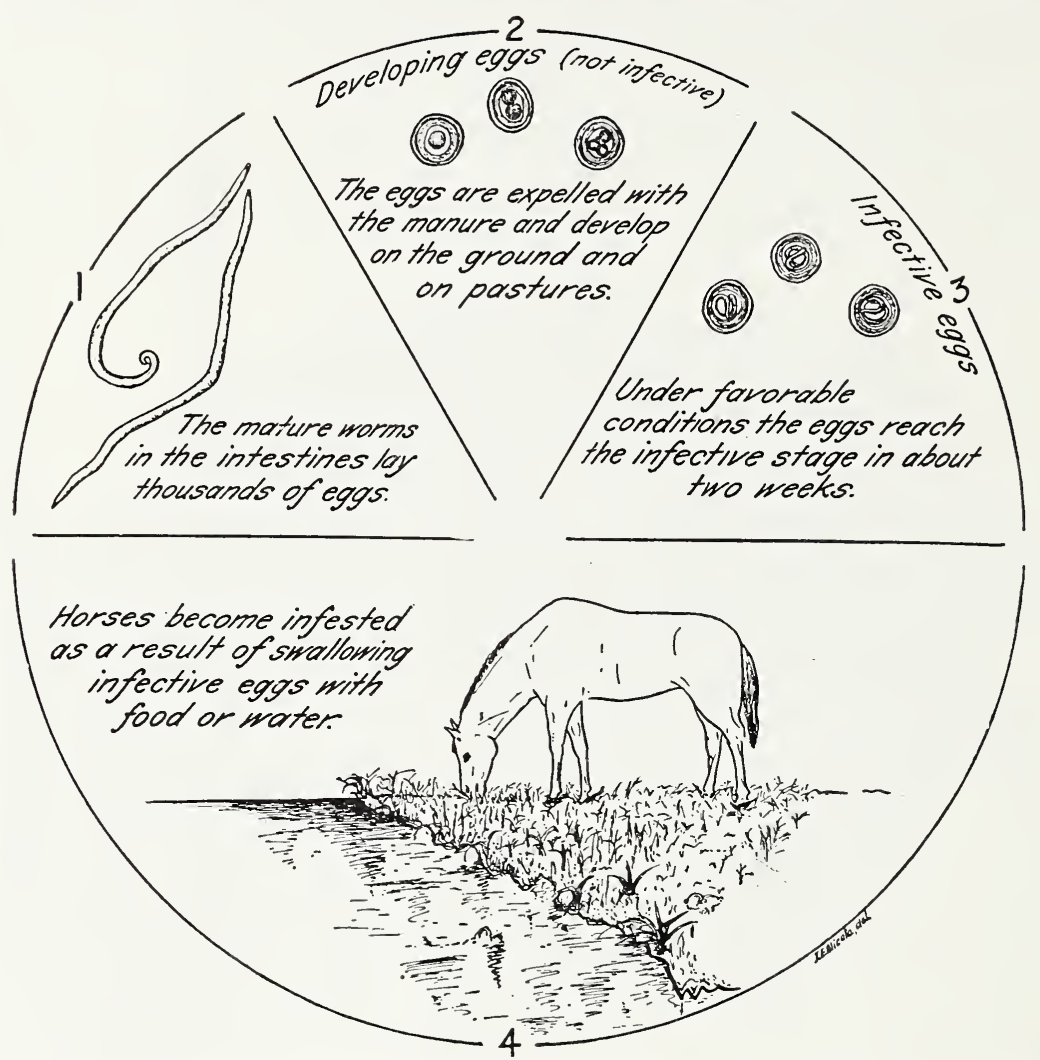

Figure 7.-Life cycle of the horse ascarid, Parascaris equorum. The eggs shown in this illustration are enlarged about 50 times.

crawl up the windpipe until they reach the back of the mouth and are then swallowed. In getting into the small intestine from the stomach for the second time, they settle down and develop to maturity in from about 2 to $2 \frac{1}{2}$ months (fig. 8).

Symptoms and lesions.-When ascarids are present in large numbers, which is likely to be the case in foals and young horses, they produce digestive disturbances of various sorts and may cause colic. These parasites frequently become entangled with one another, resulting in large masses of worms which may plug the lumen of the intestine. In an extreme condition of this sort the results may be fatal. Such an entangled mass of worms may even rupture the wall of the intestine as a result of continuous pressure on it. These worms have also been reported as being capable of perforating the wall of the intestine, presumably as a result of continually pushing their heads against it. In either case, a rupture of the intestinal wall would usually cause the death of the horse. 
In experimental infestations of horses with ascarids, fever and a cough have been observed during the early stages when the worms were present in the lungs and in the windpipe and its branches.

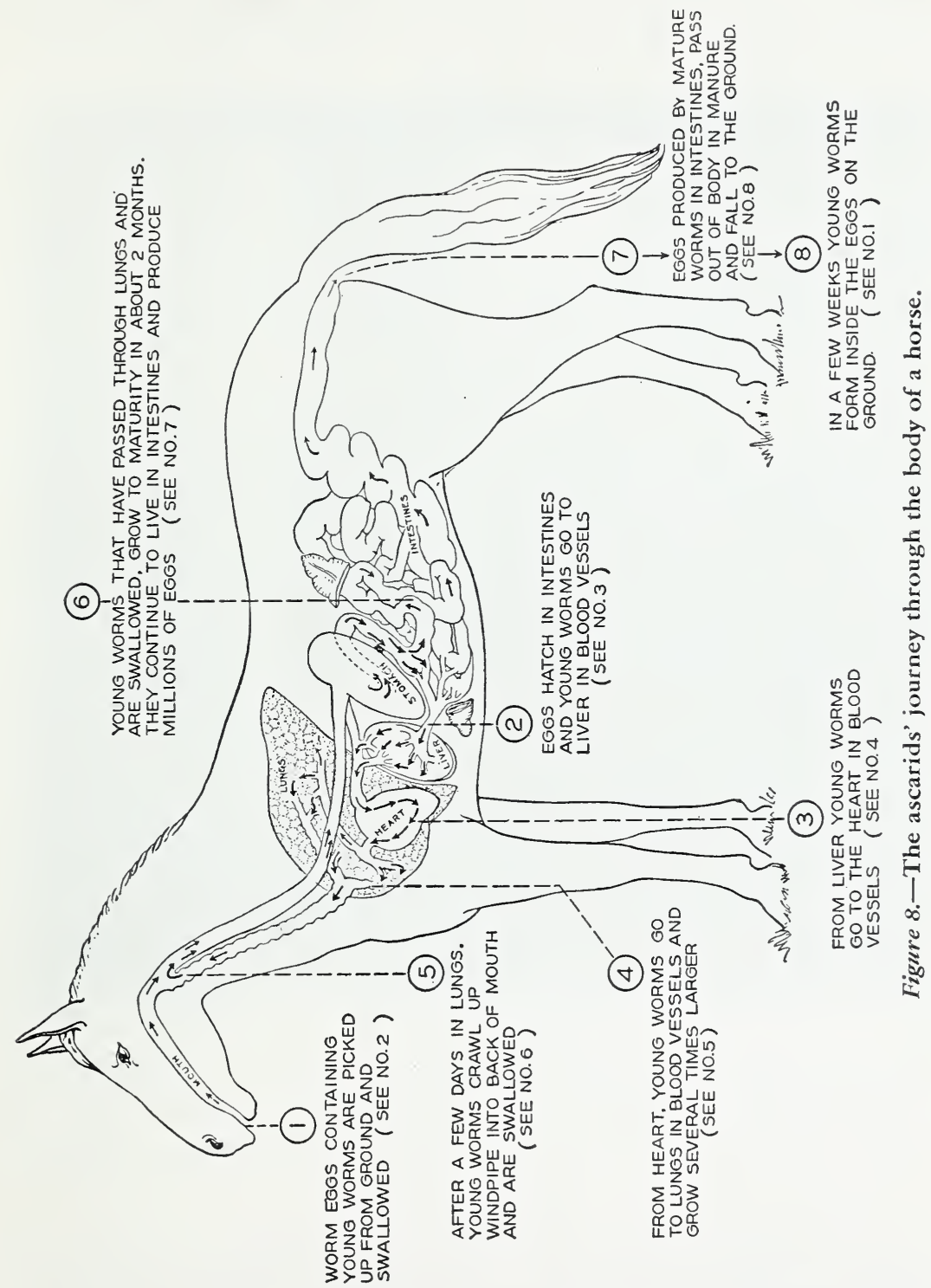

It is probable that similar symptoms are present in heary ascarid infestations which are acquired naturally in stables and on pastures. Ordinarily, ascarid infestations in foals result in unthrifty animals with rough, staring coats, and the removal of the worms frequently 
leads to marked improvement in condition, hair coat, and gain in weight.

Thus it is evident that the ascarid, both as an adult and as a wandering larva, has the capacity for causing great damage, and that its presence in horses, especially foals, is a possible source of danger. Heavy infestations, in which hundreds of worms may be present,

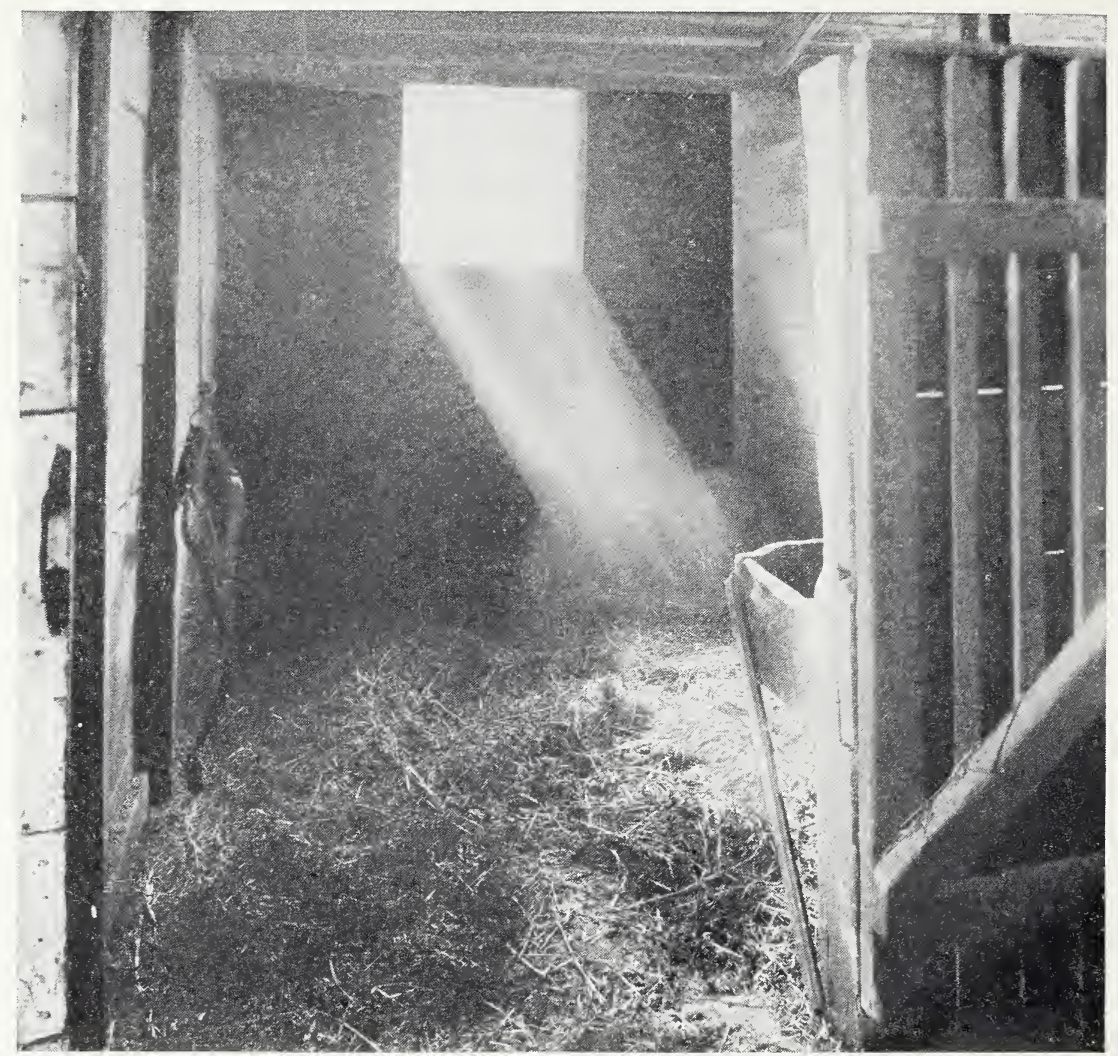

Figure 9.-Type of insanitary box stall. Note accumulation of litter and manure.

may cause illness and even death as a result of the horse's absorption of toxic products produced by the worms.

Treatrient.-Carbon disulfide is an effective remedy for the removal of ascarids from the horse. The drug is given as follows: Fast the animal for 18 hours and give carbon disulfide in a dose of 6 fluid drams (24 cubic centimeters) for a 1,000-pound animal or at a dose rate of 1.5 fluid drams (6 cubic centimeters) for each 250 pounds of weight. The worms usually pass for several days following treatment. Purgatives should not be given with this treatment. Fats and oils should be avoided as they promote the absorption and increase the toxicity of the carbon disulfide. Carbon disulfide usually produces a limited area of inflammation in the stomach of the horse. This inflammation is without serious consequences, however, and usually disappears in the course of a week or two. 
Experimental investigations indicate that carbon tetrachloride is also effective for the removal of ascarids. The animal should be fasted 18 hours and the car',on tetrachloride given in doses of from 6 to 12 fluid drams (25 to 50 cubic centimeters) for a 1,000-pound animal. This drug usually need not be accompanied with a purgative, but it is advisable to give a saline purgative immediately following the administration of carbon tetrachloride for the removal of worms, particularly ascarids, from colts. The saline purgatives, magnesium sulfate (Epsom salt) and sodium sulfate (Glauber's salt), are ordinarily administered to young animals in doses of one-half pound or less, and to mature animals in doses up to 1 pound.

Prevention.-Prevention of ascarid infestation requires special care of foals and young horses. The time to begin is before the foal is born. The foaling barn should be of sanitary construction and should be cleaned and washed with hot water and lye before the pregnant mare is placed in it. The mare and foal should be kept in a clean paddock adjoining the barn. It is best to use a paddock from which other horses have been absent for at least a year. The stable and paddock in which the mare and foal are kept should be cleaned daily if possible, litter and manure being removed.

These precautions are designed to prevent the foals from becoming heavily infested with ascarids at an early age, and before they have developed the necessary reserve vitality to cope successfully with a heavy worm infestation. When the foal is moved to a pasture it is essential to select one which is clean and that has not been used by horses for a year or longer. Proper disposal of manure and sanitary measures recommended in connection with the control of blood strongyles will also help to prevent infestation with ascarids.

While infestations with ascarids can be acquired on pastures, and often are so acquired, it is important to remember that ill-kept stables, in which manure is allowed to accumulate (fig. 9), are also the sources of heavy infestations with intestinal roundworms, pinworms, and other threadworms. Under pasture conditions many eggs and larvae succumb to drought and to other unfavorable influences which prevail in the open. In manure-laden stalls parasite eggs and larvae are largely protected from unfavorable influences and they have an abundant supply of moisture and shade and a favorable temperature for development. It is, therefore, important to pay strict attention to stable sanitation and to remove manure frequently, supply fresh bedding, clean water from sanitary watering troughs (fig. 10), and dry feed in feed boxes and racks well raised above the floor in order to prevent contamination with horse manure and consequent gross infestation with these parasites (fig. 11).

STRONGYLOIDES

Foals are commonly infested with very small and slender threadworms, Strongyloides westeri, which occur in the small intestine. These parasites, all of which are females, are whitish in color, about one-third of an inch long, and less than one two-hundred-and-fiftieths of an inch wide.

These threadworms produce numerous eggs, microscopic in size, and deposit them in the intestine of the infested foal from which they 
are eliminated in the manure. The eggs derelop very rapidly on the ground and on pastures, and the larvae which emerge from them may either transform directly into infective larvae which serve to infest other foals, or may develop into free-living males and females. As a rule both types of development take place, some larvae becoming infective while others develop into free-living adults. The latter mate on the ground or in manure and the females produce egos and deposit them on soil or in manure. In a short time, under favorable condi-

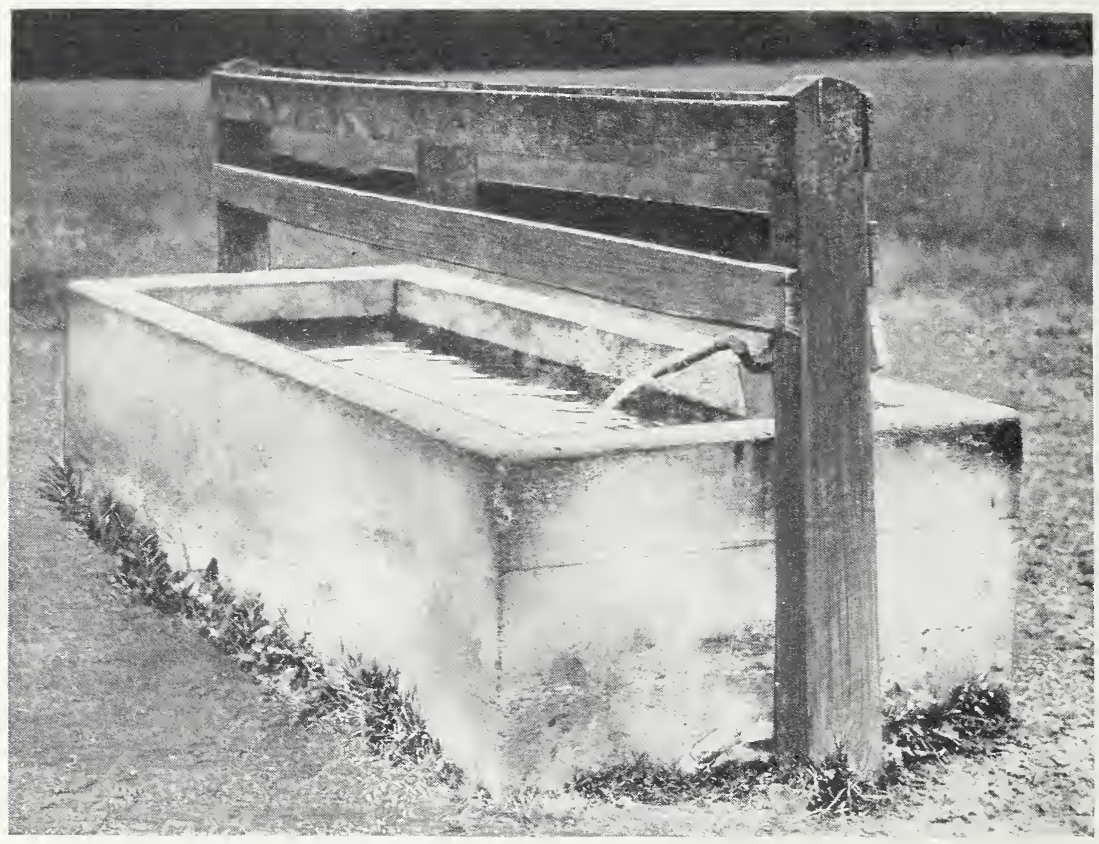

Figure 10.-Type of sanitary watering trough.

tions, larvae emerge from these eggs. These larvae become infective and are capable of infecting horses.

These parasites multiply very rapidly, the entire development on the ground taking place in a few days. The infective larvae, whether they hatched from the eggs eliminated with the feces or from the eggs produced by the free-living generation of worms, are taken in by horses with food and are also capable of penetrating the intact skin. Within about 2 weeks after the larvae have been taken up hy horses they have developed into mature females which soon begin to discharge eggs into the intestine of the host.

Symptoms and lesions. - While no definite symptoms have been described in horses as resulting from infestation with these parasites, the worms are probably responsible for diarrhea in foals. These worms make their appearance in foals earlier than do other parasites, and the infestation tends to become heavy as a result of reinfestations which may take place rapidly and often, because of the brief period required for development outside of the host. The parasites are 
usually embedded in the lining of the intestine and doubtless produce considerable irritation. The fact that the infective larvae are capable of penetrating the skin adds another complication and it is probable that foals acquire part of their infestation while lying down on pas-

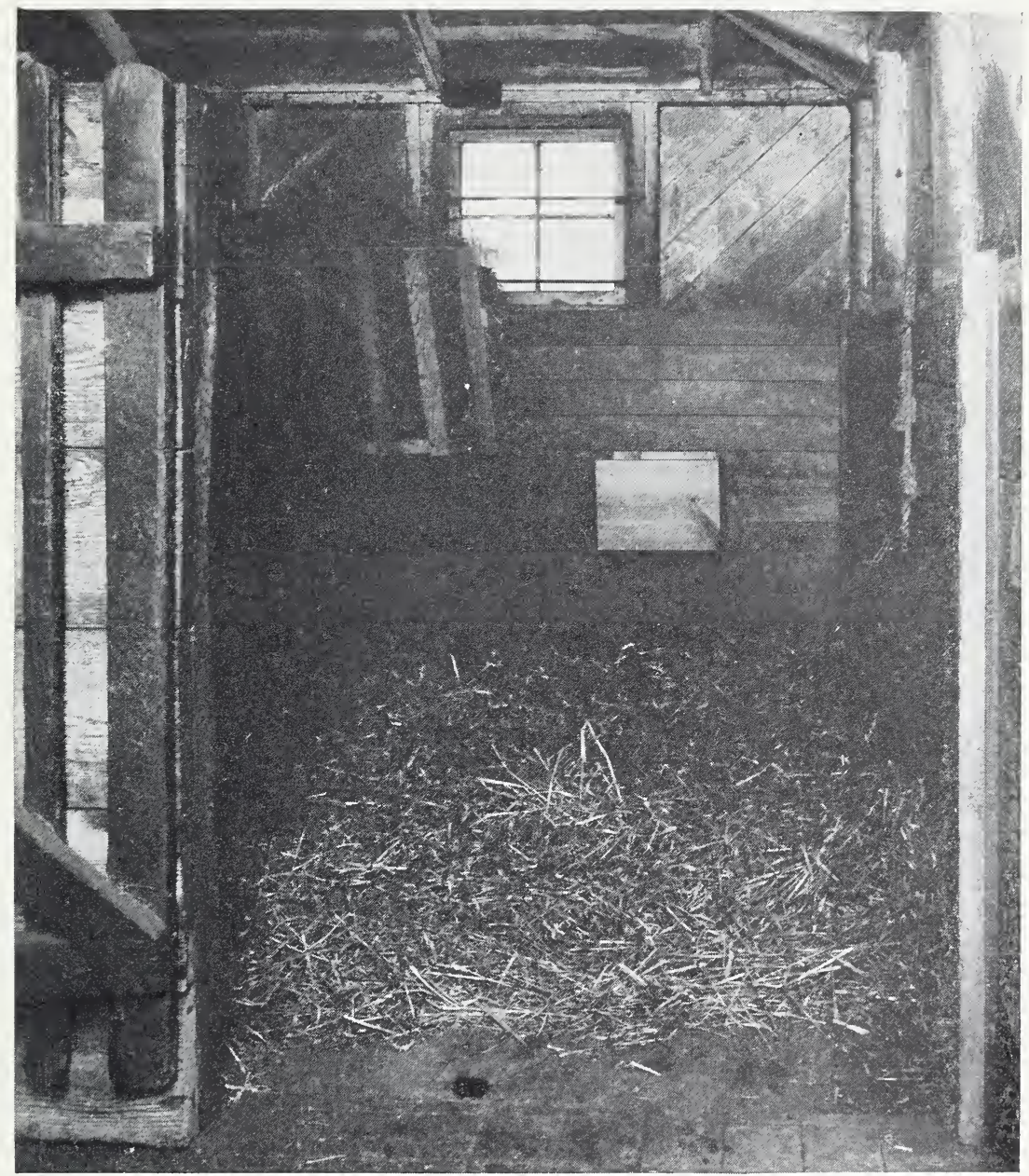

Figure 11.-Type of sanitary box stall. Note feed box and hayrack raised above the ground.

tures and in their stalls. As the larvae penetrate the skin it becomes reddened and obscure skin troubles in horses may be caused by the penetration of these worms. The larval worms may carry pathogenic bacteria into and through the skin.

Treatment.-Nothing is known concerning effective treatment for these threadworms. In severe cases of diarrhea, in foals, caused by this parasite, carbon tetrachloride is worthy of trial. The drug may be used for foals at a dose rate of 0.1 cubic centimeters per kilogram 
(2.2 pounds) of body weight or 10 cubic centimeters (2.5 fluid drams) for a 220-pound animal. In order to remove the bulk of ingesta in the sinall intestine and render the parasites more accessible to treatment, it is advisable to administer a purgative 24 hours before treatment, and to withhold feed until after the carbon tetrachloride has been given. A suitable purgative for foals consists of castor oil, 4 to 6 ounces, and neutral oil (mineral oil) 1 pint. This treatment has not had critical test to determine its precise value.

Prevention.--Prevention consists in special precautions with reference to stable sanitation, special care of foals, especially as regards clean bedding which should be changed daily, if possible. Other

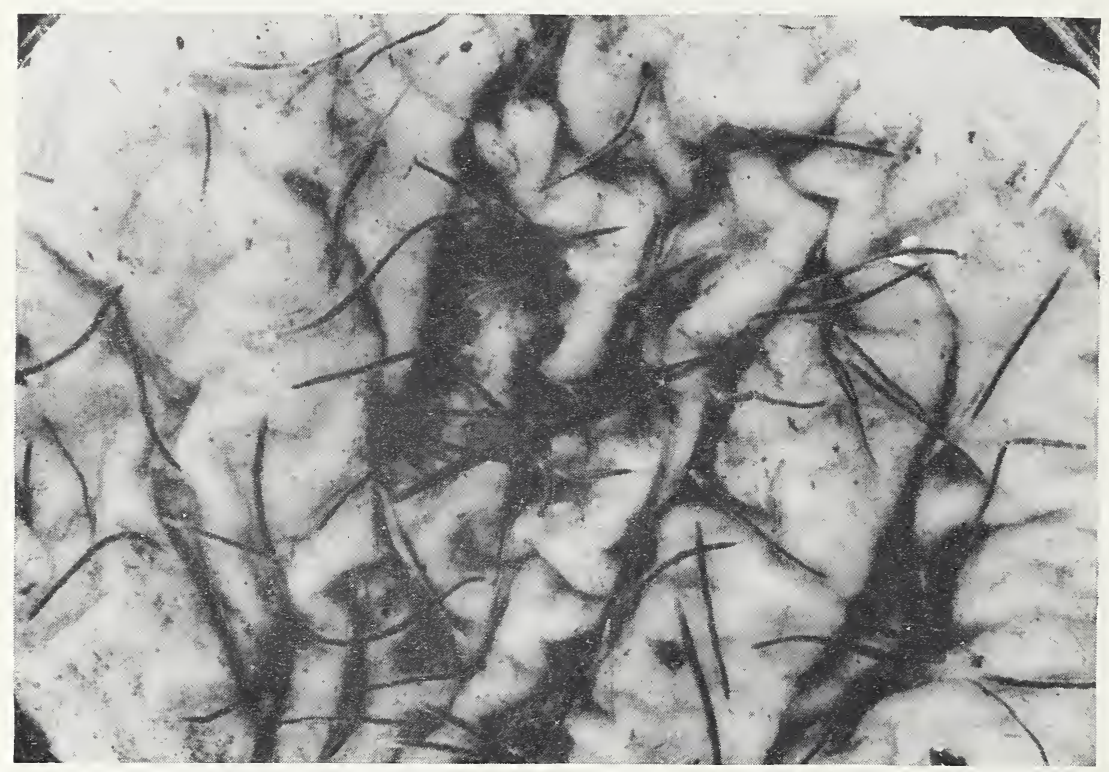

Figure 12.- Portion of the tip of the cecum of a horse, showing blood strongyles attached to the inner lining of the gut. The large worms are $S$. equinus; the small ones are $S$. vulgaris. Natural size.

preventive measures are similar to those recommended in connection with the discussion of ascarids and blood strongyles.

THE LARGE STRONGYLES OR PALISADE WORMS

The large strongyles are roundworms commonly known as blood worms, red worms, sclerostomes, or palisade worms. They are red in color and are commonly found firmly attached to the wall of the gut (fig. 12) by means of a rather formidable mouth cup. Three species of blood strongyles are of common occurrence in the colon and cecum of the horses, as follows:

The large strongyle, Strongylus equinus (fig. 13, C), is from about $1 \frac{1 / 4}{4}$ to nearly 2 inches long by about one twenty-fifth to one-twelfth of an inch wide; the mouth cup contains three teeth. The toothless strongyle, Strongylus edentatus (fig. 13, A), contains no teeth in its mouth cup; otherwise it is similar in appearance to the large strongyle, 
although it is somewhat smaller, females being about $1 \frac{1}{2}$ inches long. The single-toothed strongyle, Strongylus vulgaris (fig. 13, B), is the smallest of the three species, and is from a little over half an inch to about an inch long and less than one twenty-fifth of an inch wide; this worm contains a single tooth in its mouth cup. This tooth has two prominent, rounded projections and on casual examination two teeth appear to be present.

Life history.- The eggs of blood strongyles are discharged into the intestine of the host and are eliminated from the body with the feces (fig. 14). Under favorable conditions of temperature and moisture the eggs develop rapidly on the ground and on pastures and hatch in a day or so. The larva which emerges from each egg which develops normally, feeds on the contents of the manure in which it finds itself and after it undergoes two molts in more or less rapid succession it

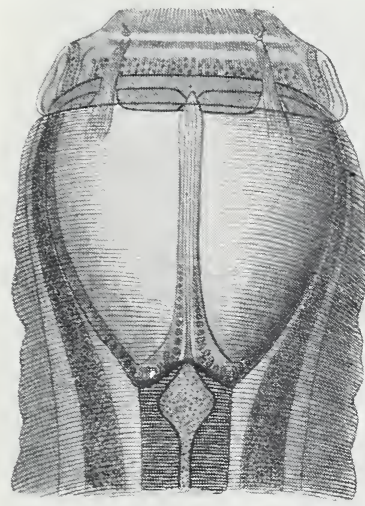

A

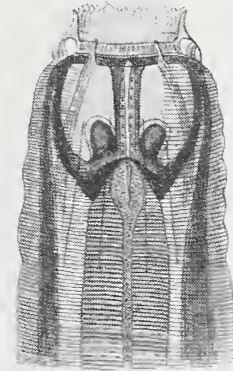

$B$

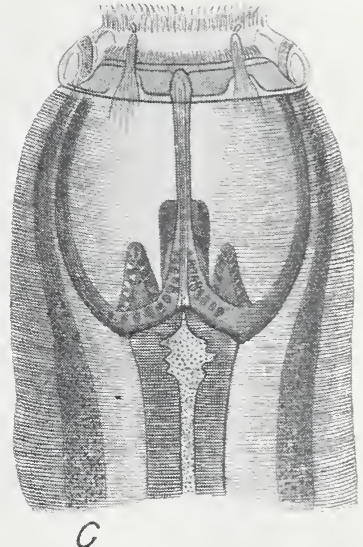

C

Figure 13.-Head ends of the three species of blood strongyles: A, S. edentatus; B, S. vulgaris; C, S. equinus. Enlarged. From Looss, 1901.

becomes infective. This entire development on the ground or on pasture takes place in a week or so during the warm months and is delayed considerably during the cold months. Lack of moisture is unfarorable to the developing eggs and larvae, but ordinarily there is sufficient moisture in horse feces to favor normal development, provided the temperature is favorable. Shade affords protection to the eggs and larvae and it is likely that direct sunlight is more or less injurious to them.

The infective larvae are very resistant to unfavorable conditions and are probably capable of maintaining themselves on pastures for long periods. They remain ordinarily in or near the manure where they hatch; however, they are doubtless scattered by rain and wind, and may reach places on pastures relatively remote from their original locations. When the air is sufficiently moist so that the grass becomes covered with a film of moisture, as happens in times of rain, dew, or fog, the larvae migrate up the grass blades and this brings them to a favorable situation to be swallowed by horses while 
grazing. So far as is known, these larvae do not penetrate the skin and must infect horses by being swallowed with grass, water, or dry food which has become contaminated with the larvae.

The course of development of these parasites after they get into the body of horses has not been definitely ascertained; it is known, however, that not all larvae, and perhaps none of them, go down directly into the cecum and colon and settle there and grow to

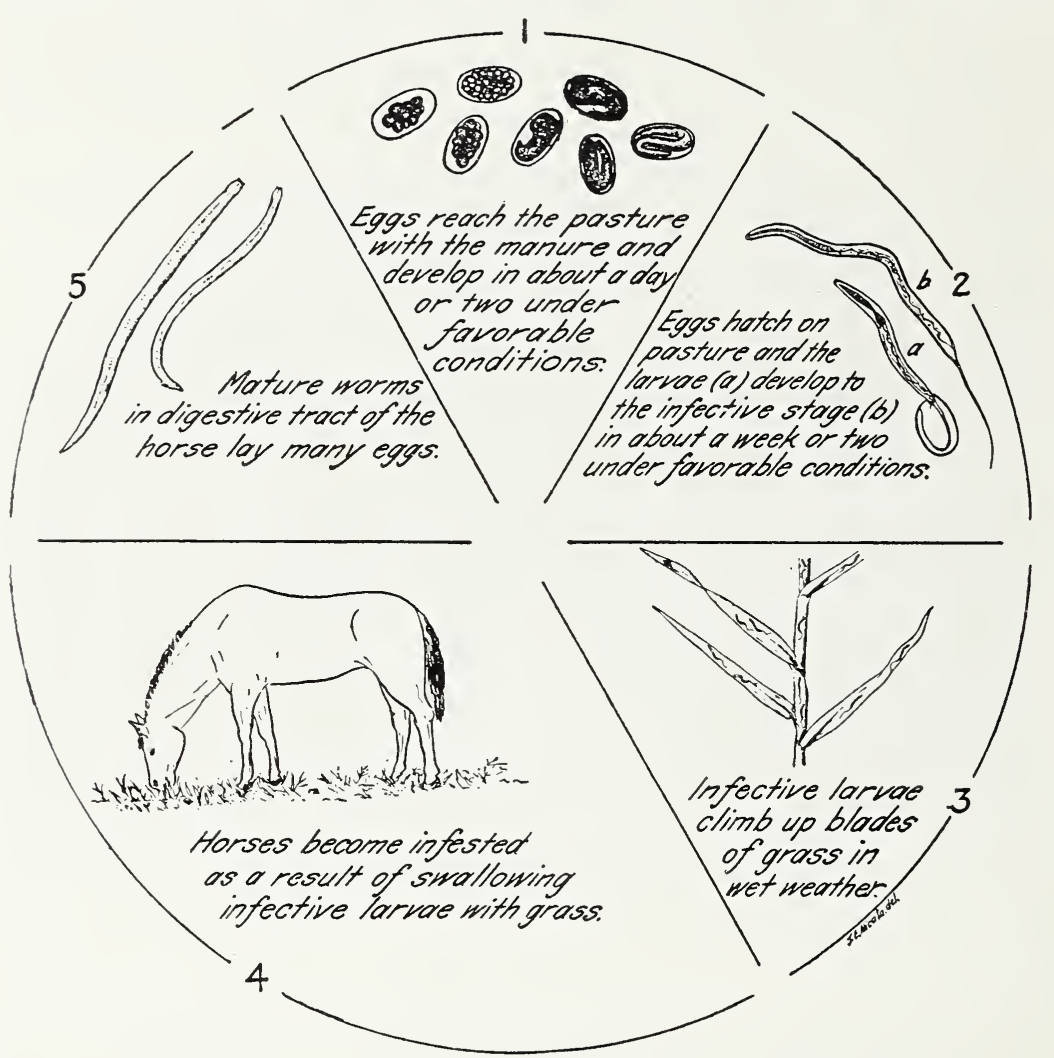

Figure 14.-Representation of the life history of one of the blood strongyles, $S$. equinus. The illustrations of the adult worms are about natural size and those of the eggs and larvae are enlarged about 75 times. This illustration is typical of the life cycle of horse strongyles generally.

maturity. On the contrary, the larvae, after entering the body of the horse, undergo extensive migrations which bring them to various organs and tissues, such as the liver, pancreas, spleen, lungs, kidneys, and other organs and tissues, from which many of the larvae probably fail to get back to the large gut. However, those larvae which return to this organ become attached to its wall and develop to fertile maturity. The eggs which are produced by the female worms and eliminated from the horse's gut with the manure start the cycle of development once more. 
From this account of the life cycle of these parasites it is evident that horses infested with blood strongyles contaminate the pastures on which they feed with the eggs produced by the worms, and that the larvae which issue from the eggs and develop to the infective stage may be swallowed by these and other horses. When horses are kept on the same pastures year after year the number of eggs and larvae gradually increases, and this contamination, accumulating

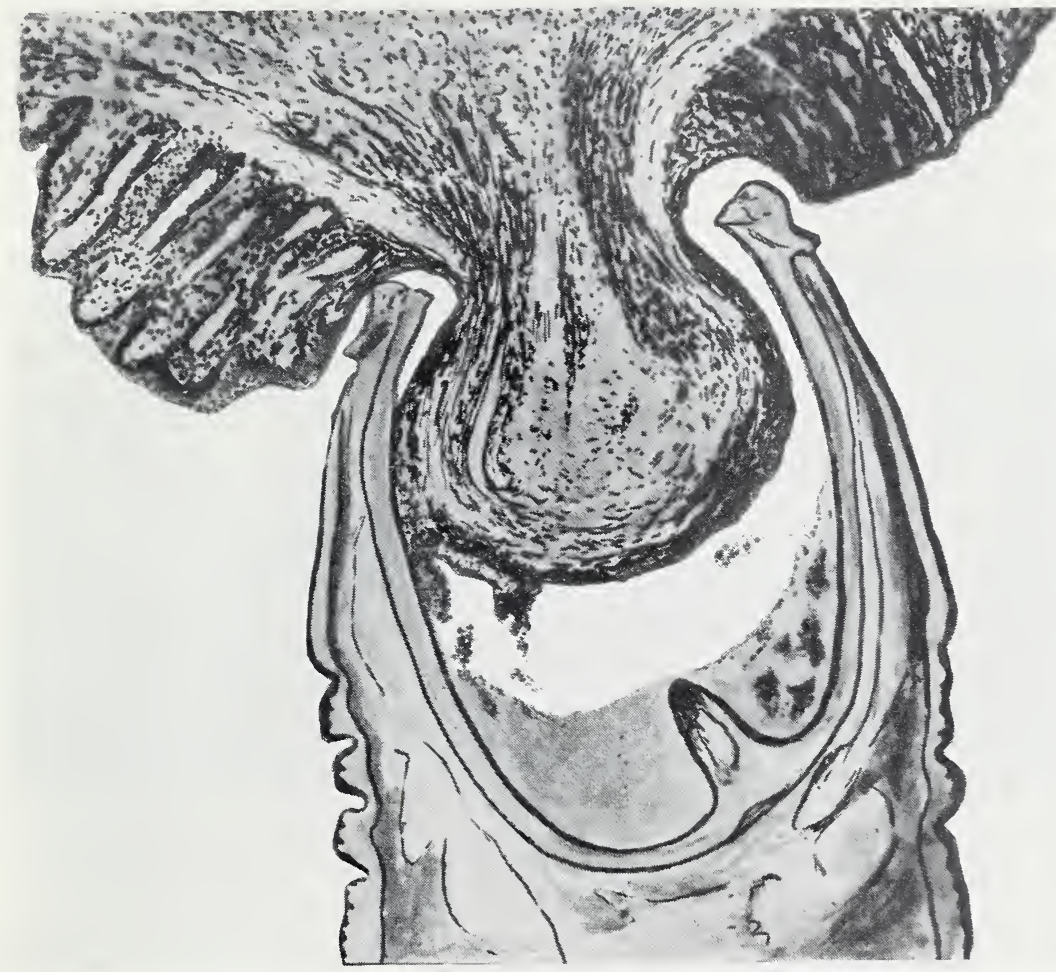

Figure 15.- Section through the wall of the large gut, showing the head end of an attached blood strongyle, $S$. equinus, with a tuft of the inner lining of gut drawn into the mouth cup of the worm. Greatly enlarged. From Wetzel, 1928.

from year to year on a given pasture, may be highly damaging to horses which are grazed there. Foals, in particular, suffer from the effects of gross parasitism acquired in this manner.

Symptoms and lesions.- The blood strongyles injure the wall of the gut to which they are attached. 'These worms suck a tuft of the inner' wall of the gut into their mouth cups (fig. 15) and abstract blood from this delicate lining. As the worms move from one place to another within the gut they expose its injured wall to the entrance of diseaseproducing bacteria. Bloodworms abstract blood from the finer blood ressels in the lining of the gut, and when many worms are present in 
a horse at the same time the loss of blood may be considerable and may lead to anemia with the usual consequnces of weakness and of watery swellings (edema) in various parts of the body. These worms also produce injuries of various sorts in the parts of the body to which they wander, such as the liver, pancreas, and other organs.

One species, the single-toothed strongyle, is especially injurious because as an immature form it settles in certain arteries, especially in the anterior mesenteric artery which supplies blood to the large gut. As a result of the presence of the worms in this blood vessel, the wall of the artery, where the worms accumulate, becomes thickened and stretches considerably to form what is known as an aneurism. An aneurism is a spindle-shaped, cylindrical, or globular dilation of a blood ressel and often contains a heary deposit of fibrin inside. In the horse it may attain the size of a child's head (fig. 16).

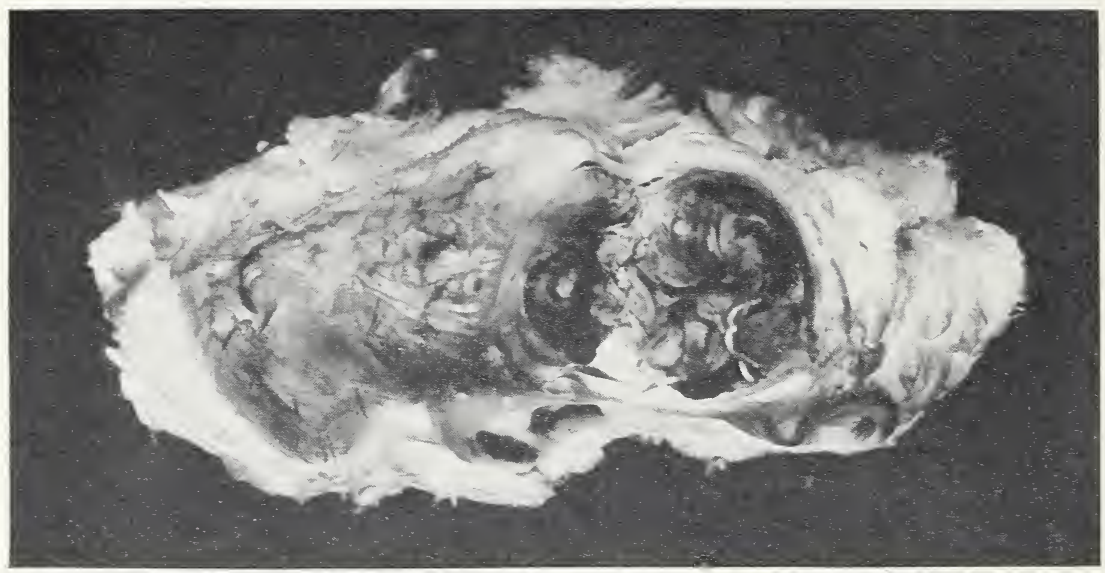

Figure 16.-A small aneurism of the anterior mesenteric artery of the horse, partly cut open to show worms and the heavy deposit of fibrin inside. The worms are immature forms of Strongylus vulgaris. Natural size.

An aneurism interferes to a considerable extent with the circulation of blood through the affected artery, because the heary deposits of fibrin inside may almost obliterate the lumen of the blood ressel. This condition results in a diminished blood supply to the large intestine; when the intestine becomes anemic as a result of this it becomes predisposed to colic, twist, and intussusception, the last being a condition in which part of the gut slips into an adjoining part. When a piece of fibrin deposit in the aneurism breaks loose, it may be carried in the circulation to a terminal portion of an artery and may lodge there as a plug. As a consequence, the circulation to a part of the large gut may be completely shut off. Such a condition interferes with the functions of the large gut, produces an anemic condition with the consequences noted above, and in extreme cases may produce death. It is believed that most cases of colic in horses result from such disturbances in the blood circulation of the gut. If the plug forms in a hind leg it may cause a form of intermittent lameness. Aside from the injuries described, mixed parasitic infestation, known 
as strongylidosis, results when blood strongyles occur in large numbers and in association with other species of roundworms in the large gut, particularly when horses are kept on permanent pastures.

This condition is widespread in horses and is usually more injurious to foals and young horses than to older horses. Strongylidosis is frequently mistaken for infectious anemia or swamp fever and cases diagnosed as swamp fever, in many instances, have cleared up following the removal of worms by medicinal treatment. The common symptoms of strongylidosis are diarrhea, weakness, and emaciation. The digestive disturbances result from the irritation to the lining of the gut produced by the parasites. At first the diarrhea is slight and the soft manure has a bad odor and contains poorly digested food material; later the diarrhea becomes more pronounced, with softer feces. The appetite, which is irregular at first, becomes poorer and finally the horses are off feed. As a result of their weakened condition, affected horses find difficulty in chewing, may throw out mouthfuls of feed, and then reject feed altogether. This leads to further emaciation which becomes very marked. As the disease progresses the bones become prominent, the coat becomes rough, the eyes are sunken, and the animal becomes greatly weakened (fig. 17). With these symptoms there are marked changes in various tissues and organs of the body.

The working capacity of horses which are suffering from strongylidosis is decreased considerably even before the symptoms become very pronounced, and in the absence of treatment such horses are able to do less and less work as the disease progresses. It has been found that when horses are treated for the removal of parasites many of the symptoms described above disappear, the animals take on weight, regain their working capacity, and make general improvement.

Treatment.-Phenothiazine is very effective for the removal of large strongyles and is a drug which has come into wide use as an equine anthelmintic. The fact that horses occasionally react unfavorably to this drug has not been fully explained, although there is evidence that animals on a low protein diet may be more susceptible to the development of anemia, jaundice, and other symptoms of intoxication than animals maintained on rations of adequate protein content. During recent years, moreover, most of the risk of employing phenothiazine as an anthelmintic for horses has been overcome by administering smaller doses than had been used formerly and by giving the drug in divided doses. The optimum dose for a mature horse of average size is about 30 grams of the chemical, and it may be administered in gelatin capsules, as a drench in suitable suspension, or admixed with grain feed. Moreover, if the last method is followed, effective medication may be achieved by the administration in feed of 5 grams of phenothiazine daily for from 5 to 7 days in succession as an alternative to giving the full dose at one time, the period depending somewhat upon the size of the animal. Preparatory fasting and purgation are not necessary when phenothiazine is used, but it is desirable in the interests of safety to guard against constipation when the treatment is given. The addition of bran to the feed mixture is helpful in this respect. Although heavily parasitized equines should be given therapeutic $811770^{\circ}-49-4$ 
doses of phenothiazine as described above, experience has shown that strongyles can be kept at minimum numbers by allowing pastured animals free access to loose mixtures containing about 1 part of phenothiazine to approximately 40 parts of granular salt or mineral mixture. It is generally necessary to encourage consumption of the mixture by adding, from time to time, a small amount of grain feed. Animals on

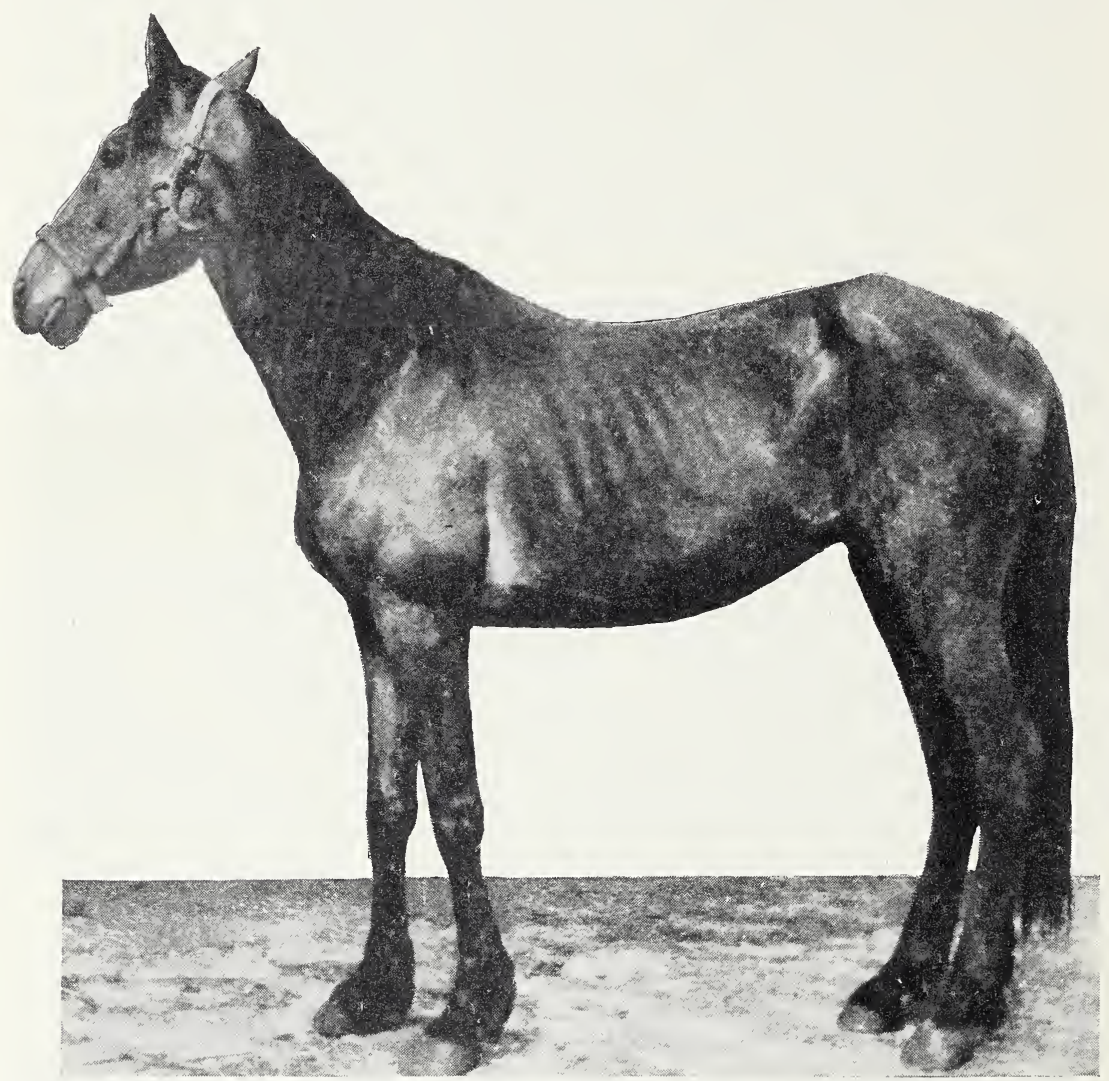

Figure 17.- Horse suffering from gross infestation with parasites (strongylidosis) Note marked emaciation. Following treatment for the removal of parasites, this horse made a good recovery.

such a regimen should be given some surveillance in order that therapeutic treatments may be given, if necessary, to animals which may not consume sufficient amounts of the free-choice mixtures.

Another drug often used for the removal of large strongyles is oil of chenopodium. It is very effective and usually safe, but horses are sometimes slow to recover from the after effects of the medication. When this drug is used, the animal should be fasted for 24 to 36 hours before treatment and the drug should be given in a dose of from 4 to 5 fluid drams (16 to 20 cubic centimeters) for a 1,000 pound animal, or at a dose rate of 1 fluid dram (4 cubic centimeters) 
for each 250 pounds of weight, immediately preceded or followed by 1 quart of raw linseed oil or by an aloes ball. Cases of excessive purgation have been reported in some instances following the use of raw linseed oil. It is possible that this undesirable action is due to impurities in the product; consequently a good grade of oil should be used. A mixture, said to be without the undesirable effects of raw linseed oil, has been recommended as follows: For weanlings, castor oil, 4 to 6 ounces, and mineral oil, 1 pint; for yearlings and 2-year-olds, castor oil, 6 to 8 ounces, and mineral oil, 1 pint; for 3 -year-olds and older, castor oil, 8 to 10 ounces, and mineral oil, $1 \frac{1}{2}$ pints.

Carbon tetrachloride also is of value for the removal of large strongyles and is safer than oil of chenopodium for treating pregnant mares. The dose is 6 to 12 fluid drams (25 to 50 cubic centimeters) for a 1,000-pound animal. Normal butylidene chloride is also effective. It is administered after a preliminary fast at a dose rate of 3 fluid ounces (90 cubic centimeters) for a 1,000-pound animal, and followed in 5 hours by 1 quart of raw linsecd oil. A closely related chemical, normal butyl chloride, is equally effective and is less expensive but has the disadvantage of being metabolized into a very unpleasant smelling substance. This drug is used at a dose rate of approximately

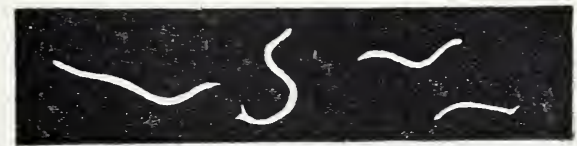

Figure 18.-Small strongyles of the horse. 3 fluid ounces (90 cubic centimeters) for a 1,000-pound animal and is administered in from 8 to 10 times its volume of raw linseed oil.

Prevention.-Preventive measures designed to control strongyles consist (1) in rotation of pastures, so far as possible, avoiding low and wet pastures, and (2) sanitation of stables to prevent larvae from developing to the infective stage and from contaminating the feed and water. This is accomplished by daily removal of manure from stables, supplying the feed in boxes and racks well raised above the floor, and supplying clean water. The disposal of stable manure is an important preventive measure, as is shown elsewhere in this circular. Little can be accomplished in the way of pasture sanitation except on farms where thoroughbred or other valuable horses are raised. On these farms the removal of manure deposits from pastures may be practiced, as this procedure will remove almost all the parasite material before it can develop and spread. Such a procedure is necessarily troublesome and expensive and can be undertaken only by breeders to whom the question of expense is of secondary importance. The arerage breeder will have to resort to simpler and less radical measures, such as avoiding the overstocking of pastures, frequent rotation of pastures, and special attention to foals. Where overstocking and the use of wet pastures are unavoidable, and rotation is impossible, reliance must be placed on treatment as often as necessary for control.

Horse breeders, and even the general farmer, should pay considerable attention to the sanitation of paddocks in which the newly born foals are kept. The foals should be kept there for several weeks before they are put on pasture. Removal of manure from the paddocks, at least once a week, will cut down the supply of eggs and larvae to which 
the foals would otherwise be exposed. This precaution will help to tide the foals orer the most critical period of their lives.

Young animals require special care much the same as children. Above everything else, a wholesome food supply and clean surroundings are the best safeguards against disease. Special precautions to prevent foals from becoming parasitized are essential parts of sound management in horse-breeding establishments and on the average farm.

THE SMALL STRONGYLES

In addition to the blood strongyles or palisade worms, horses are commonly infested with numerous closely related species of strongrles, which are much smaller in most cases than blood strongrles, though
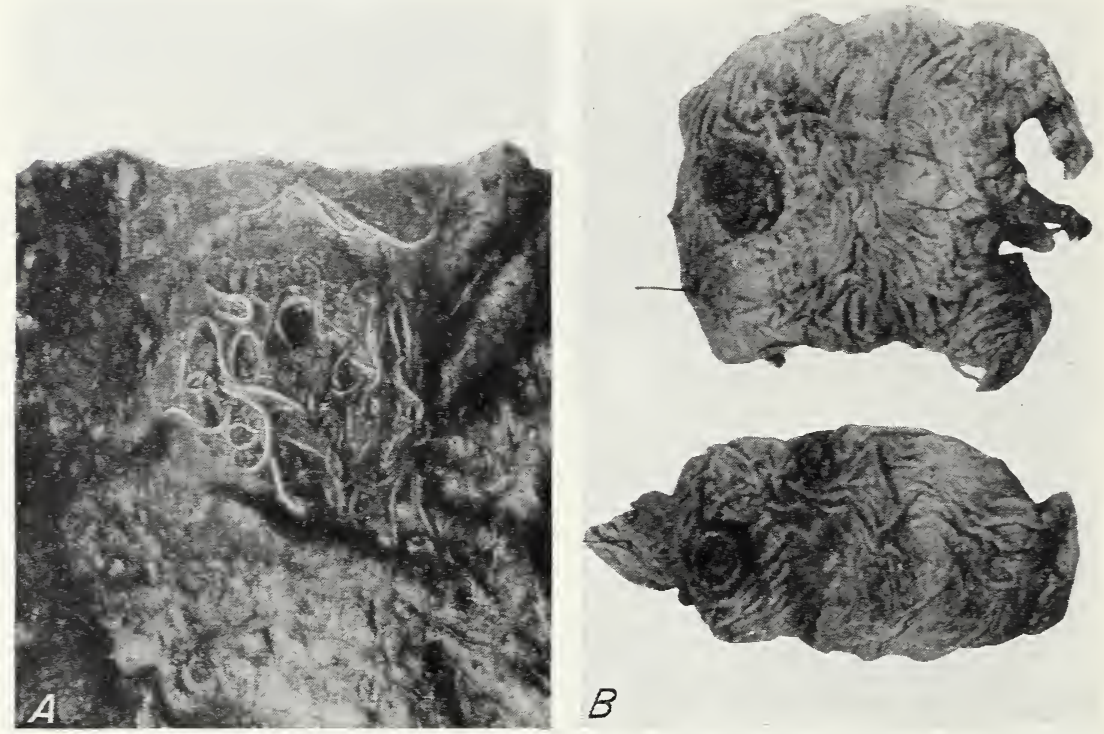

Figure 19.-Lesions produced by one of the smaller horse strongyles: $A$, enlarged view of lesion with worms, Triodontophorus tenuicollis, surrounding it; $B$, types of lesions. (From Ransom and Hadwen, 1918.)

some are almost as large (fig. 18). These worms occur in the colon and cecum and some of them produce visible injuries. One species, Triodontopkorus tenuicollis, produces rather severe ulcers in the wall of the colon (fig. 19), probably by means of the sharp teeth in their mouth cups. Some of the smaller horse strongyles, the many species known as crlicostomes, species of Trichonema or Cylicostomum, are usually about a half inch or less in length and gravish white in color, and occur attached to the gut wall or free in the contents of the large intestine of the horse. These worms do not feed on blood, at least ordinarily, but they may feed on the mucosa of the large intestine. The immature forms of some cylicostomes occur in nodules in the wall of the large intestine.

The small strongyles of the horse contribute to the picture of gross parasitism, and together with the large strongyles, are responsible for 
digestive disturbances, weakness, emaciation, and anemia resulting from severe infestations with parasites.

The life histories of the smaller strongyles have not been studied in detail, but the indicated control measures with reference to these worms are the same as those recommended in connection with the control of blood strongyles.

Treatment.-The treatments recommended for the removal of large strongyles are also used for the removal of small strongyles.

The pinworms, Oxyuris equi, which are commonly seen in horses are the females. These are relatively long, whitish worms with a very long and slender tail (fig. 20). The males are small and inconspicuous and are seldom found. The females may attain a length of 3 to 6 inches. They occur in the large bowel.

Life history. The gravid females pass out with the manure and then deposit their eggs, instead of depositing them in the bowel. Sometimes the females hang on to the anal opening and extrude their eggs in the region

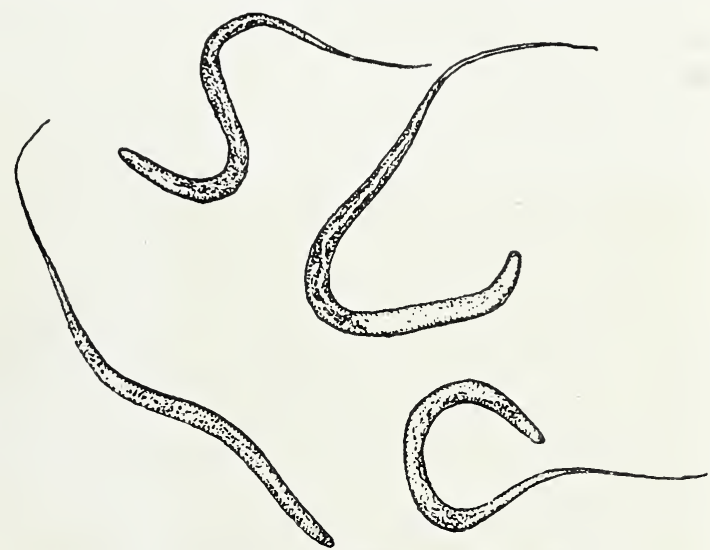

Figure 20.-Pinworms, Oxyuris equi (females), of the horse. Natural size. around the anus; the eggs may adhere in this region in the form of yellow crusts. In either case, the eggs develop outside of the body, as do those of the large intestinal roundworm, and in a few days they reach the infection stage. Each egg which develops normally contains a small worm within the shell. Ordinarily the eggs do not hatch outside the horse's body. Horses become infested with pinworms as a result of swallowing the infective eggs in feed or water.

Symptoms and lesions. The most evident injury produced by pinworms is the irritation of the anus, which causes a horse to rub its tail and buttocks against any convenient object. This irritation may result from the passage of the worms out of the anus, from the crushing of the female worms as they pass out, or from some irritant property of the eggs. It is also reported that aside from causing this irritation, pinworms are responsible for digestive disturbances, and that, when present in large numbers, they produce anemia.

Treatment.- - Oil of chenopodium, administered as for large strongyles, is effective for the removal of pinworms from the horse. Phenothiazine also is reasonably effective. Oil of turpentine is also an effective treatment and should be given in a dose of 2 fluid ounces ( 60 cubic centimeters) for a 1,000-pound animal, immediately preceded or followed by 1 quart of raw linseed oil or by the proper dose of the 
mixture of castor oil and mineral oil, as given under the treatment for large strongyles.

Prevention.-Preventive measures with reference to the control of pinworms are similar to those recommended for the large intestinal roundworms and for blood strongyles.

\section{LUNGWORMS}

Lungworms, Dictyocaulus arnfieldi, are long, slender, whitish worms and range from about 1 inch to a little over 2 inches in length. They occur in the bronchi and in the bronchioles (branches of the bronchi).

Life history. - The egg contains an embryo at the time it is deposited by the female. The eggs hatch in the lungs, and presumably the larvae are coughed up, swallowed, and eliminated from the body with the manure. It is also likely that larvae are expelled with mucus during coughing or sneezing. In either event, the larvae undergo their development on the ground and attain the infective stage in a few days. On the basis of what is known regarding the method of infestation with closely related species of lungworms which occur in cattle and sheep, one may assume that horses become infested with lungworms as a result of swallowing the infective larvae with feed or water.

Symptoms.-When few lungworms are present in a horse, definite symptoms are not produced. In heavy infestations the parasites produce bronchitis, and the most outstanding symptom of this condition is a cough. Excessive coughing weakens an animal, and in severe cases it may result in death.

Treatment.-Medicinal treatment for lungworm infestation is unsatisfactory.

Nursing treatment usually gives better results and is without harm to the animal. Nursing treatment consists in providing nourishing food, pure and uncontaminated drinking water, salt, clean, sanitary quarters, and adequate shelter. The affected animals should be removed from contaminated pastures and placed in lots or pastures which are not infested with parasite eggs and larvae. This plan of treatment is designed to remove the animal from areas in which it is subject to gross reinfestation and improve its condition.

Prevention.--Preventive measures are similar to those recommended for the control of blood strongyles and the large intestinal roundworm. The manure must be disposed of in a manner that keeps the infective material away from the horse.

THE NECK THREADWORM

The large ligament of the horse's neck, known to veterinarians as the ligamentum nuchae, is frequently parasitized by a long, slender threadworm, Onchocerca cervicalis. The exact length of these worms has not been determined owing to the difficulty of extracting them from the ligament without breaking them.

Life history.- - It has been determined recently that certain biting flies, commonly known as midges, are the intermediate hosts of this parasite. The midges take up the larval worms in the course of piercing the skin of infested horses and, after a period of 24 to 25 days, the infested midges contain larvae capable of infecting suscepti- 
ble horses. Presumably, horses become infested as a result of being bitten by midges harboring the infective larvae.

Symptoms and lesions.-These worms apparently act as irritants to the tissues and thus weaken their resistance to the attacks of disease germs. There is reason to believe that this may lead to the development of poll evil and fistulous withers.

Treatment. - Surgical and medicinal treatment may be employed where poll evil or fistulous withers is present, but there is no treatment for the destruction of the worms.

Prevention.-While it is difficult to prevent horses from being attacked by midges in localities where these pests occur, the avoidance of swampy pastures and of pastures which contain streams should prove beneficial in controlling the neck threadworm.

THREADWORMS OF THE ABDOMINAL CAVITY

Threadworms, Setaria equina, of the body cavity of the horse, also known as filarids or setarids, are relatively long and slender (fig. 21) and occur in various locations outside the alimentary canal of the horse. The filarid of the body cavity of the horse is from a little over 2 to about 5 inches in length and whitish in appearance and usually occurs in the abdominal cavity, but it has also been reported from other parts of the horse's body. Immature forms of this filarid, as well as of the closely related filarid of cattle, sometimes occur in the eyes of horses as the so-called eye worm or "snake in the eye."

Life history. - The life history of this worm has not been definitely ascertained. From what is known of the life histories of related forms, occurring in other animals, it is probable that horse filarids are transmitted by blood-sucking insects.

Symptoms and lesions.-The adult worms do not appear to do much damage and are not

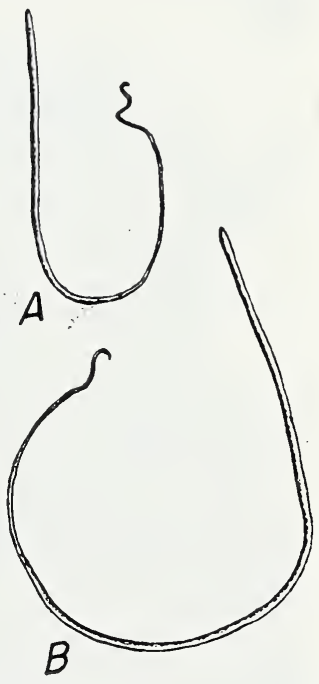

Figure 21.-Threadworms, Setaria equi$n a$, of the abdominal cavity of the horse: $A$, male; $B$, female. Natural size. known to be responsible for any definite symptoms. When the immature worms get into the eye, which apparently occurs only rarely in the United States, they produce considerable irritation and in time may produce blindness.

Treatment.-The presence of this parasite in the abdominal cavity is seldom diagnosed during life and no treatment for it is known. When the worm is present in the eye, it may be removed surgically under local anesthesia.

Prevention.--In the absence of definite knowledge concerning the mode of transmission of these parasites, no definite control measures can be recommended. Measures to prevent attacks by biting flies, the prevention of fly breeding, and the reduction of flies by spraying barns and stables with suitable preparations of $\mathrm{DD}^{\mathrm{T}} \mathrm{T}$ or other insecticides may be of value. 


\section{Bots ${ }^{4}$}

Bots are maggots of certain flies (fig. 22) known as botflies. Three species of bots commonly occur in horses in the United States.

The common botfly, Gasterophilus intestinalis. occurs in practically all parts of the United States. The bots, or parasitic larrae, are reddish in color and are attached to the white covering of the left sac of the stomach or along the ridge between the right and left sacs of the stomach. The adult fly deposits its eggs on the hairs of the inside of

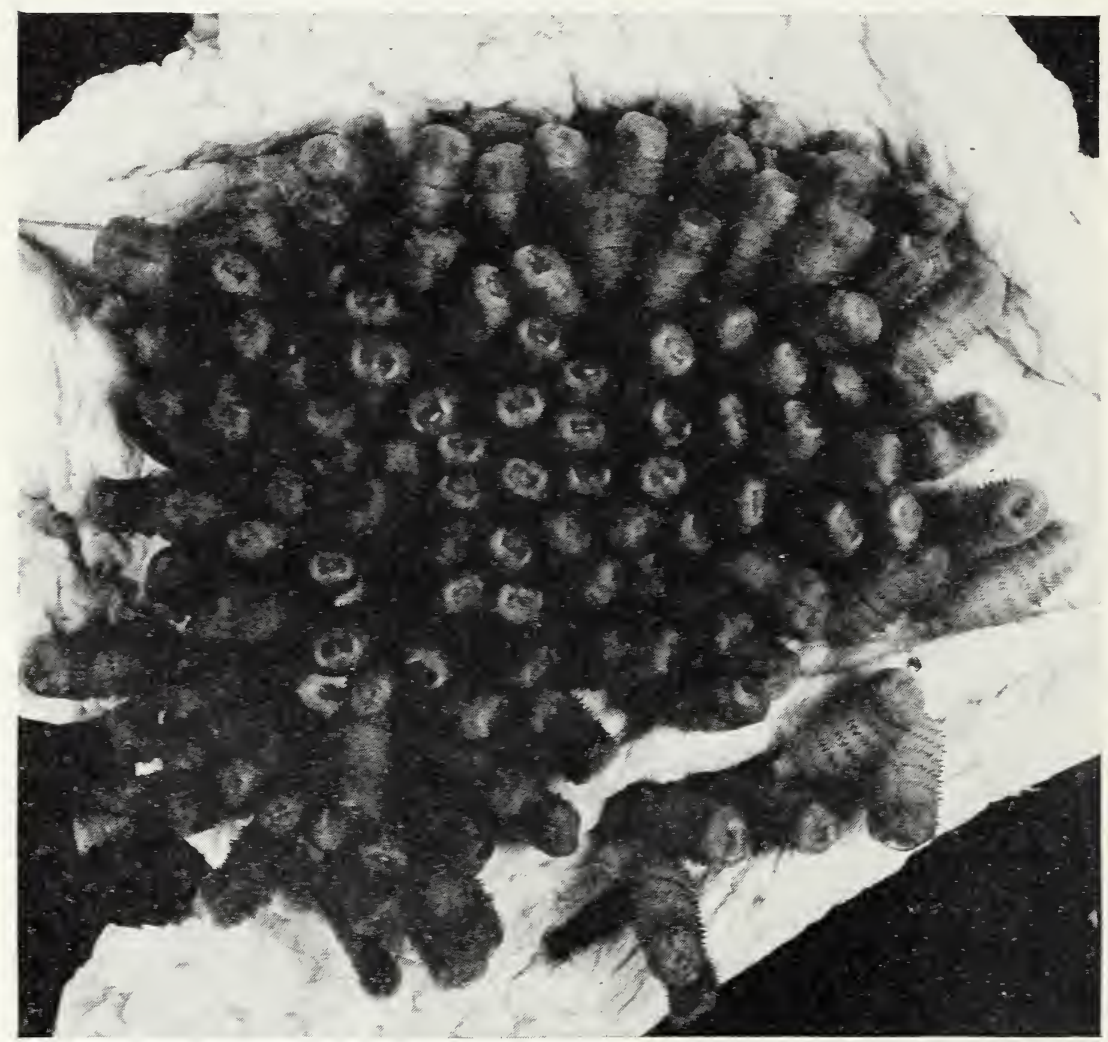

Figure 22.-Portion of a horse's stomach, showing bots, Gastropbilus intestinalis. attached to the inner lining of the stomach wall. Natural size.

the front legs, breast, mane, belly, and even the hind legs. The throat botfly, or chin fly, $G$. nasalis, is rather widely distributed in the United States and is especially common in the Rocky Mountain region. The adult fly of this species deposits its eggs under the jaw of the horse, and in so doing causes much annorance to horses. The bots are vellowish in color and are attached to that portion of the stomach which joins the small intestine and also to the wall of the upper part of the intestine. The nose fly, G. hemorrhoidalis, has a more limited distribution than

\footnotetext{
${ }^{4}$ For more detailed information concerning horse bots and their prevention consult Farmers Bulletin 1j03, The Horse Bots and Their Control.
} 
the other two species and is mostly confined to the North Central States and certain of the Rocky Mountain States, but it is spreading in all directions. The adult flies of this species deposit their eggs along the edge of the lips and cause much annoyance to horses. The nose fly is the most dangerous of the botflies and is the one which is responsible for many accidents because its annoyance makes horses panicky and causes them to run away. The bots of this species occur in the stomach and duodenum, and when full grown also attach in the rectum.

Life history.-The eggs are glued to the hair of horses by the adult flies. The eggs of the common horse bot are hatched apparently by the biting and licking of the horse, and are taken into the mouth on the lips and tongue. The small spiny bots burrow into the mucous membrane of the mouth, especially the tongue, where they remain from 21 to 28 days before emerging and passing on to the stomach. The habits of the nose bot are apparently very similar to those of the common bot. The eggs of the chin fly hatch without friction and the young bots crawl to and enter the mouth. Whether the throat bot penetrates the tongue is not yet known. When the bots reach the stomach they attach themselves to its wall and remain there for a period of from 8 to 12 months during which time they attain their complete larval development and then pass out of the body. While the common bot and the throat bot pass out of the body directly with the manure, the nose bot reattaches itself to the rectum on its way out, then becomes detached and reattaches itself to the anus, where it may remain for 3 or 4 days, and finally drops to the ground. Usually all fully developed bots pass out of the body by October and those which overwinter in the horse are the young forms. These bots pupate in the ground and 20 to 70 days later emerge as winged flies, ready to mate and to begin the process of egg laying once more.

Symptoms and lesions.-Bots often occur in large numbers, and it is not unusual to find several hundred of these maggots attached to the stomach wall of a horse. These parasites have large mouth hooks by means of which they attach themselves to the lining of the stomach and upper intestine. They also bear spines on much of their body surface. With this armature they are capable of irritating the lining of the digestive tract with which they are in contact and of producing considerable irritation and injury. The attachment of nose bots to the rectum and edge of the anus before they pass out is very annoying and horses have been known to dislocate bones in the tail in their attempts to obtain relief from this annoyance.

The damage caused by the adult flies, especially the nose fly, is very great. Runaways may lead to serious accidents and farming is often interrupted by the inability to work the frightened horses.

Treatment.-Carbon disulfide is the most effective treatment for the removal of bots. Carbon tetrachloride may also be used but is much less effective. These drugs should be used in accordance with the recommendations given under the treatment for large intestinal roundworms.

Tetrachlorethylene frequently will remove from 50 to 75 percent of the bots when the drug is used in single doses of 1 to 2.3 fluid ounces (30 to 70 cubic centimeters) for a 1,000-pound animal after fasting the horse 18 hours. The drug should not be accompanied by a purg- 
ative. Cases of dizziness have been reported occasionally in horses dosed with tetrachlorethylene, but this dizziness soon passes off.

Treatments should be administered in the winter after the adult flies are killed by frost and all the bots are present in the stomach or upper part of the small intestine. The best time is about 1 month after the first freezing weather lasting 24 hours or longer. One month before the internal medication an application of one of the coal-tar creosote dips in about 2 percent dilution to the parts of the animal bearing the bot eggs is advised so as to destroy the eggs and thus aroid subsequent infestation.

Prevention.-Preventive measures against infestation with bots include the use of rarious protective mechanical derices to prevent the flies from depositing their eggs on horses, shaving the hair where the eggs hare been deposited, and the destruction of the eggs by certain medicinal applications to the skin.

\section{Disposal of Manure}

Inasmuch as manure is the source from which horses acquire nearly all their common parasites, either directly or indirectly, the proper disposal of manure from stables and yards is an essential part of sound management. Indiscriminate spreading of fresh horse manure on horse pastures to supply fertilizer is an unwise and unsafe procedure because it disseminates infective eggs and larvae of parasites which have developed in stables and yards. Owners of thoroughbred horse farms who have learned of the danger to horses as a result of spreading fresh manure on pastures have discontinued this practice and are discarding manure as fertilizer altogether. Such a procedure is too wasteful for farm practice, as the manure must be utilized and is safe after it has been stored for a time. Conditions of storage should permit the spontaneous heating process, which is destructive to eggs and larvae of parasitic worms, to act throughout the manure for a sufficient time.

When manure is stored in open piles it heats in the middle but remains cold on the surface. Such manure is dangerous, so far as parasite transmission is concerned, because the eggs and larvae present on the surface of the manure pile escape destruction. It is, therefore, important that the outer 3 or 4 inches of exposed manure piles be turned over erery week or so in order to bury the exposed manure under the inner material of the pile and sterilize it by heating. If this is not done, the manure should not be placed on any field to which horses may have access even months later, as the eggs and larvae of many species of parasites are longlived and rery resistant to unfarorable influences. It has been determined that the eggs and larvae of parasites present in manure can be more certainly and easily destroyed if the manure is stored in closed containers or boxes, having double walls and a double floor, with a 4 - to 6 -inch space between the walls and floor filled with sawdust and, the top of the container covered with a well-fitted lid (fig. 23). It is essential that the containers be tight in order to retain as much heat as possible; the greater the heat dereloped and retained in manure boxes the sooner the eggs and larvae will be destroyed. 
The sawdust acts as an insulator, but even with this precaution it is desirable to use tongue-and-groore lumber in the construction of manure containers in order to make them tight. Concrete boxes will not serve, as the manure at the sides is chilled and there is not heating enough to destroy parasites.

For practical purposes manure which has been kept in such containers for at least 2 weeks may be considered free from living eggs

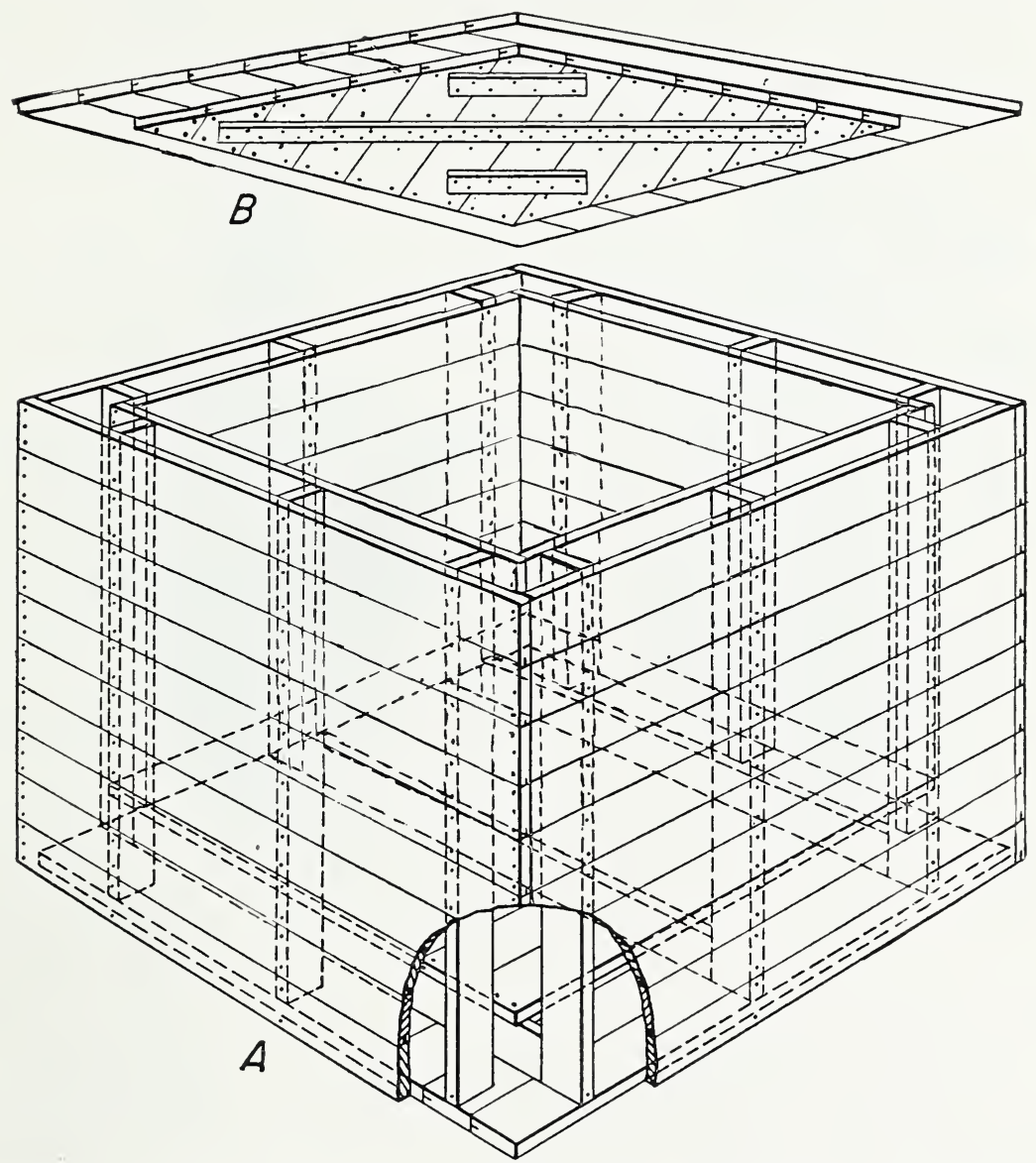

Figure 23.-A, Box with double walls and double floor for sterilizing horse manure; $B$, tight-fitting lid. The space between walls and floor must be filled with sawdust to insure insulation.

and larvae of parasites and may be safely spread on pastures. Several manure boxes constructed on the above principles have been in operation at the Beltsville station of the Bureau of Animal Industry with successful results. These boxes have double-walled doors to facilitate the removal of the manure after it has been sterilized.

In default of such measures, spread horse manure on fields which are to be pastured by animals other than horses, or plow it under. 


\section{Summary of Control Measures}

The most common and most troublesome parasites of horses in the United States lire, at least part of their lires, in the digestire tract, either free in the lumen, attached to the walls, or embedded in the lining of the wall. These parasites produce eggs which pass out in the manure on to pastures, the floors of stalls, and other places. All such worm infestations in horses trace back to manure as the original source.

Manure must be regarded as dangerous, and control measures should be designed to prevent contaminating the feed and water with manure so far as it is possible to do so. The following measures are designed to reduce the possibilities of gross infestations of horses with parasites:

Pastures should be stocked lightly. Heary stocking means more manure, and this, in turn, means a heavier concentration of parasite eggs and larrae.

Sloping hillside pastures are better than level ones. Rain and melting snow tend to wash manure down to some extent from sloping pastures. The bottom of a sloping pasture is dangerous because it has a high concentration of eggs and larvae. It should be fenced off if possible.

Rotation of pastures is desirable and should be used so far as arailable pastures permit. It is important to remember that permanent pastures perpetuate parasites.

Stock rotation is a sound procedure. For the most part the parasites of cattle. sheep, and goats are not transmissible to horses, and vice versa. More horses to a pasture on which cattle or sheep have been grazing and move cattle and sheep to a horse pasture in alternate vears.

Keep stables clean; remove manure often, daily if possible; supply clean bedding and change it often; and supply clean water.

Feed from boxes well raised above the ground and from overhead racks. Do not feed from the ground, because the feed will become contaminated with manure.

Do not spread fresh manure on pastures. Hold stable manure, preferably in double-walled, closed containers, until it has undergone a heating process. If you have an open manure pile, turn the outer few inches of the manure once a week. Bury it under the inner portion. If rou have no facillties for keeping manure, haul it to areas used by animals other than those that produced the manure or plow it in for field crops.

Take steps to reduce the fly nusiance by using insecticidal sprays, storing manure in closed containers, or employing other preventive measures recommended by the United States Department of Agriculture.

Remember that foals require special treatment to tide them orer the critical period of infancy. If you expect to raise sound horses, protect the foals.

Consult a veterinarian when your horses require medicinal treatment for the removal of parasites. 


\section{EXTERNAL PARASITES OF HORSES}

\section{Horse Lice}

Usually lice are restricted to one host species or to closely related species, and horse lice will not live on animals other than horses, mules, and asses. Three kinds of lice are commonly found on horses in the United States. The first and most important of these is the
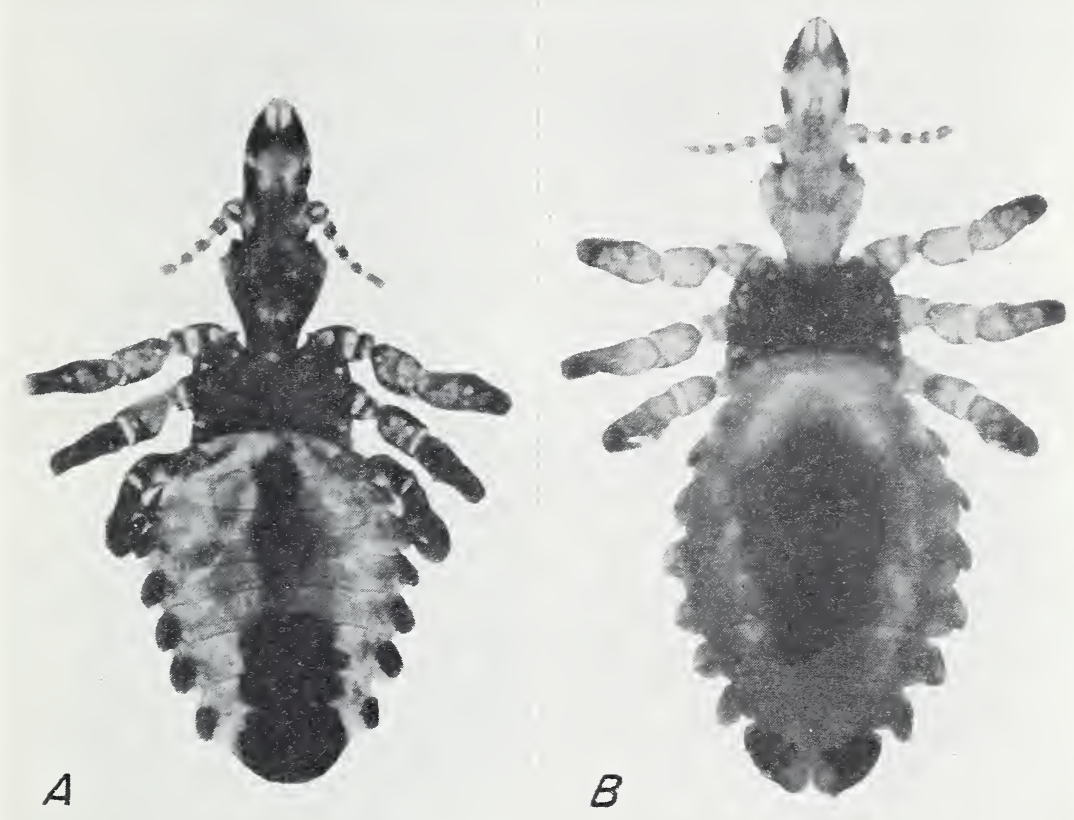

Figure 24.-Sucking louse of horses (Haematopinus asini): A, Male; B, female (Magnified 25 times.)

blood-sucking species known technically as Haematopinus asini. The two other species, Bovicola pilosa and $B$. parumpilosa, are biting lice.

The sucking louse of the horse is easily distinguished from the biting species. It is much larger and has a long, pointed head, whereas the biting lice have short, blunt, rounded heads (figs. 24 and 25). The sucking louse apparently causes more damage than the biting lice and it is more difficult to eradicate.

\section{NATURE AND HABITS}

The eggs or nits of the sucking louse are attached firmly to the hairs, usually close to the skin, and they hatch on the animal in from 11 to 20 days, the majority hatching in from 12 to 14 days. The young lice reach maturity and the females begin laying eggs when they are 11 or 12 days old. The lice pass their lives on horses, and can live only about 2 or 3 days when off a host animal. 
The biting lice of horses deposit their eggs in the same general manner as the sucking louse. The period of incubation is probably from 8 to 10 days. These lice may live as long as 10 days when separated from the host animal if kept on tufts of hair, but most of them die in 5 or 6 days.

During cold weather, when the hair on horses is long, lice increase very rapidly; but when the animals shed their hair in the spring the
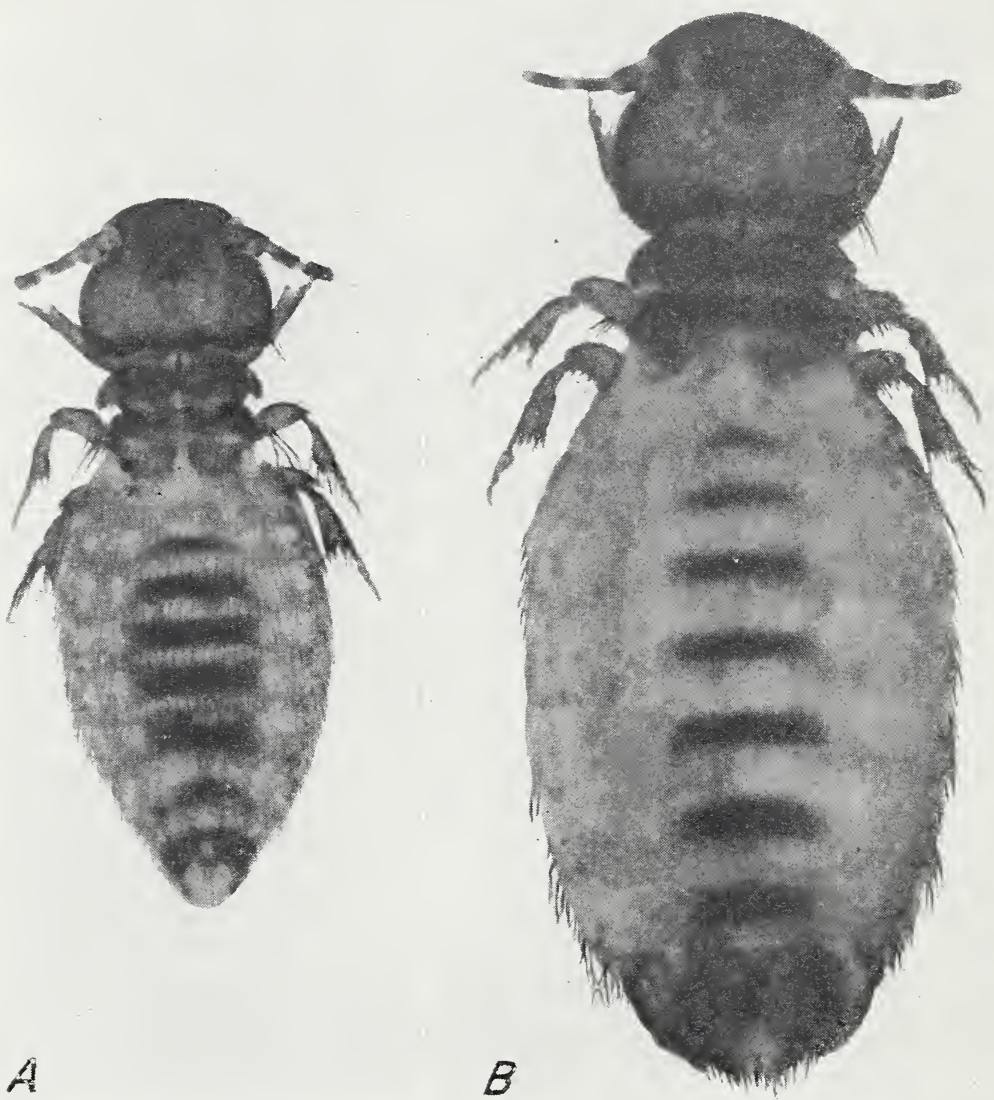

Figure 25.-Biting louse of horses (Bovicola pilosa): A, Male; B, female, (Magnified 25 times.)

parasites seem to disappear. Some of the lice usually remain on the animals throughout the summer, but not in sufficient numbers to cause annoyance or to be easily detected. The animals, therefore, usually go into the winter infested. Since the most efficacious remedies are liquid dips, which cannot be used safely on horses during cold weather, fall dipping should be practiced whenerer horses have been lousy at shedding time. 
Symptoms.-The sucking louse obtains its food by puncturing the skin of the horse and sucking blood and lymph. When not feeding it mores about on the hair and skin. The biting lice do not suck blood from the host, but apparently feed on particles of hair, scales, and exudations from the skin. The irritation and itching which result from either or both methods of feeding are shown by the efforts of infested animals to obtain relief. Infested horses rub and bite themselves, and often kick and stamp and manifest extreme uneasiness and irritation.

The coat becomes rough; the frequent rubbing destroys the hair in patches and often causes bruises or wounds in the skin. If lice are present in sufficient numbers to cause considerable itching and irritation they can usually be found, especially if the infested animal is placed in the sunshine. All species of horse lice are easily seen with the naked eye and often congregate in groups or colonies on parts of the animal. The farorite locations are the sides of the neck, around the flanks, and under the jaws. In cases of gross infestation, however, lice may be found all orer the body and leos.

When horses are lousy, close examination should be made to learn what kind or species of lice is present. It is not especially important, from a practical standpoint, to distinguish between the two species of biting lice, but it is important to know whether the animals are infested with biting or sucking lice or with both kinds.

Method of spreading.-More cases of infestation originate from direct contact with lousy animals than in any other way. Under reasonably good sanitary conditions stables, rards, and other premises which have contained lousy horses are not a source of great danger to horses free from lice. It seems probable, however, that occasionally lice may become dislodged from their host and drop on mangers, floors, etc., and from these locations find their way to a new host.

When separated from their host sucking lice live about 3 days, the biting lice not to exceed 10 days. Ordinarily egos are not deposited except on the host, but when the hair to which they are attached is removed and kept under farorable conditions they may continue to hatch for as long as 20 days. The newly hatched lice live only 2 or 3 days unless they find a host. It is therefore possible for premises to remain infested for 25 or 30 dars from the time they were occupied by infested horses. When lousy horses are clipped the hair should be burned and the ground or floor where the clippings dropped should be thoroughly treated with an insecticide.

Lice may be carried from one animal to another on currycombs, brushes, and blankets, or by harness, saddles, and other equipment moved directly from a lousy horse to one free from lice. Currycombs and brushes should be treated each time a horse is groomed. Ḧarness, saddles, blankets, and other equipment used on lousy animals should not be put on horses that are free from lice unless the equipment has been thoroughly cleansed.

When cleaning stables and yards remove all litter and manure down to a smooth surface, then spray well with a good insecticide. The coal-tar creosote dips, diluted in accordance with the instructions printed on the label of the container, are suitable for ridding premises of the lice. 
Treatment.-None of the dips recommended for use in treating horses can be depended on to eradicate lice at one dipping. The first dipping, if properly done, will probably kill all the lice, but it may not destroy all the eggs. The nits or eggs which survive dipping often hatch, forming a new generation of lice. This new generation should be destroyed by a second dipping after hatching is completed and before the young lice become mature and begin depositing eggs. Since these two periods overlap somewhat and vary greatly, and because the periods from hatching to egg laying are different for the sucking and biting lice, it is impossible on this basis to calculate the exact period that should elapse between dippings. Young lice appear on dipped animals as early as the third day after the first dipping, and since the average period of maturation is about 12 days it seems evident that the second dipping should be given in about 2 weeks. Experience has shown that two dippings with an interval of from 14 to 16 days usually can be depended on to control both sucking and biting lice.

The dips commonly used for destroying lice on horses, mules, and asses, named in the order of their effectiveness, are arsenical solution, coal-tar creosote, and nicotine. The arsenical solution is poisonous, and unless handled with due precaution injury to man and animal may result. When properly used, however, it is the most dependable known dip for destroying lice. The coal-tar creosote dip is effective when used in reasonably good water. Two dippings, from 14 to 16 days apart, in either of these dips can usually be depended on to eliminate horse lice. Two dippings in nicotine solution will ordinarily free horses from lice. On account of the difficulties in dipping in cold weather, and the unsatisfactory nature of hand treatments, most of them only palliative, it is advisable to dip for lice, when they are present, in the fall of the year before the onset of cold weather.

Applications of dusting powders or sprays are often of value for holding lice in check. Dusting powders may be applied with a dust gun, a shaker, or by hand, and mixtures of wettable sulfur, talc, or pyrophyllite containing approximately 10 percent of any of the following insecticides are efficacious; namely, finely ground derris or cube powder containing from 3 to 5 percent rotenone, DDT powder, finely ground sabadilla seed, or benzene hexachloride containing at least 10 percent of the gamma isomer. Such powders should be used sparingly, and not allowed to get into the eyes, nose, mouth, or into the feed of the animals. Biting lice can be destroyed with sodium fluoride. Care should be taken not to apply sodium fluoride too freely around the natural body openings or where the skin is very thin and hairless, and not to rub it into the skin.

Some of the newer insecticides which appear to be particularly efficacious against lice, notably DDT, benzene hexachloride, and certain of the thiocyanates, are marketed in forms that are suitable for application as sprays. These should be used according to directions accompanying them.

Fumigating horses with the fumes from burning sulfur (sulfur dioxide) will kill horse lice, but many of the eggs survive, and two treatments 2 weeks apart are necessary to effect eradication. The ad- 
vantage of this method of treatment is that it can be used when the weather is too cold for dipping. The disadrantages are that it is necessary to have a gastight inclosure and the animal's eyes and.

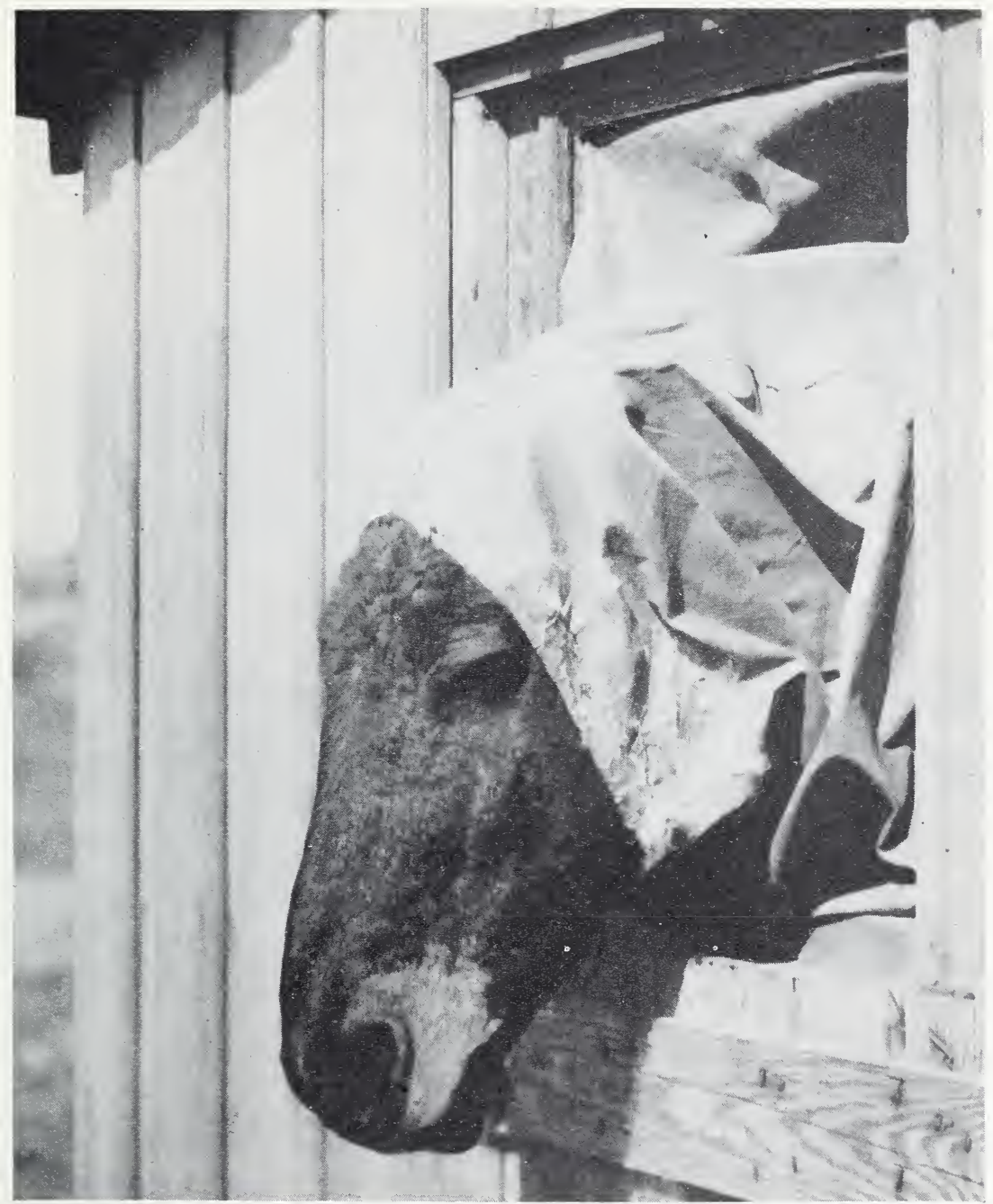

Figure 26.-Fumigation with sulfur gas for lice. Eyes and nostrils must be kept away from the gas. Part of head not fumigated must be hand treated.

nostrils must be kept away from the gas. A concentration of about 1 percent sulfur dioxide is necessary to kill the parasites, and serious injury or death may result if the gas comes in contact with the eyes or nostrils. After fumigation it is necessary to hand treat that part of the head that was not fumigated (fig. 26). 


\section{Horse Mange}

Scabies in horses, commonly known as mange, itch, or scab, is a name given to a group of contagious skin diseases caused by minute

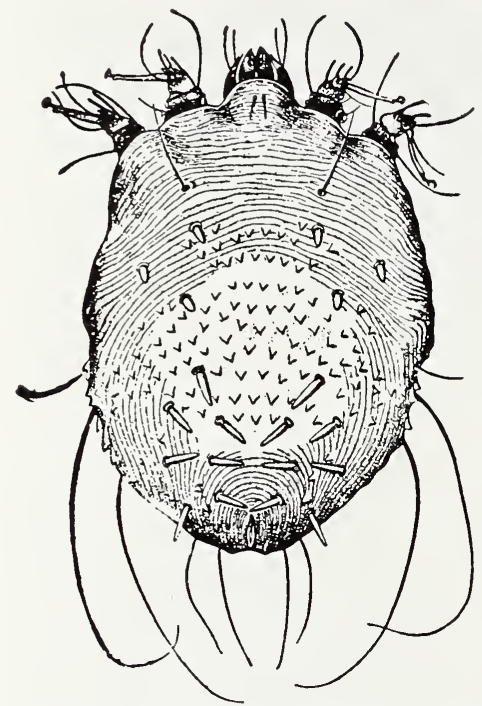

Figure 27.-Sarcoptic mange mite. Female. (Magnified 100 times.)

parasites known as mites, which live on or in the skin. Four species of these parasites are found on domesticated animals, but horses are commonly affected by only three of them. These parasites are classified zoologically in three different genera-Sarcoptes, Psoroptes, and Chorioptes. Mites of the first two genera are shown in figures 27 and 30 .

In obtaining their food from the host and preparing a resting place in or on the tissues, the mites cause wounds or lesions in the skin. As each kind of mite possesses distinctive habits, the location and nature of the lesions in the early stages are more or less characteristic. Each kind of mite, therefore, causes a specific kind of mange which is named after the generic name of the mite. Thus we have in horses sarcoptic, psoroptic, and chorioptic mange. The sarcoptic variety is the one most common on horses in the United States

\section{SARCOPTIC MANGE}

SARCOPTIC MANGE MITE

The mites which cause sarcoptic or common mange of horses are small, white, or yellowish parasites known technically as Sarcoptes scabiei equi (fig. 27). The female when full grown measures about one-fiftieth and the male about one-sixtieth of an inch in length. When placed on a dark background they are visible to the naked eye. The general form of the body is more nearly round than oval, and the bluntly rounded head is as broad as it is long. When mature, these mites have four pairs of short, thick legs, the fourth pair and usually the third pair also not extending beyond the margin of the body. Under a high-power microscope a number of short, backward-projecting spines may be seen on the upper surface of the body.

The sarcoptic mites penetrate the upper layer of the skin and excavate burrows or galleries in which the mating of the sexes occurs and the eggs are laid. Each female may lay from 10 to 25 eggs during the egg-laying period, which probably lasts from 12 to 15 days. When that period is completed the female dies in her burrow. The entire life cycle is passed on the body of the host animal. The eggs hatch in from 3 to 10 days, and the young mites after passing through several molts reach maturity and begin laying eggs in 10 or 12 days. 
As the arerage period of incubation on the animal is about 4 days, and the average period after hatching until egg laying begins is 11 davs, a new generation of mites may be produced in about 15 days. If the first treatment or dipping could be depended on to kill all the mites on the animal the time for the second treatment could be calculated accurately. Unfortunately, the first treatment usually does not kill all the sarcoptic mites on the animal because of the difficulty of

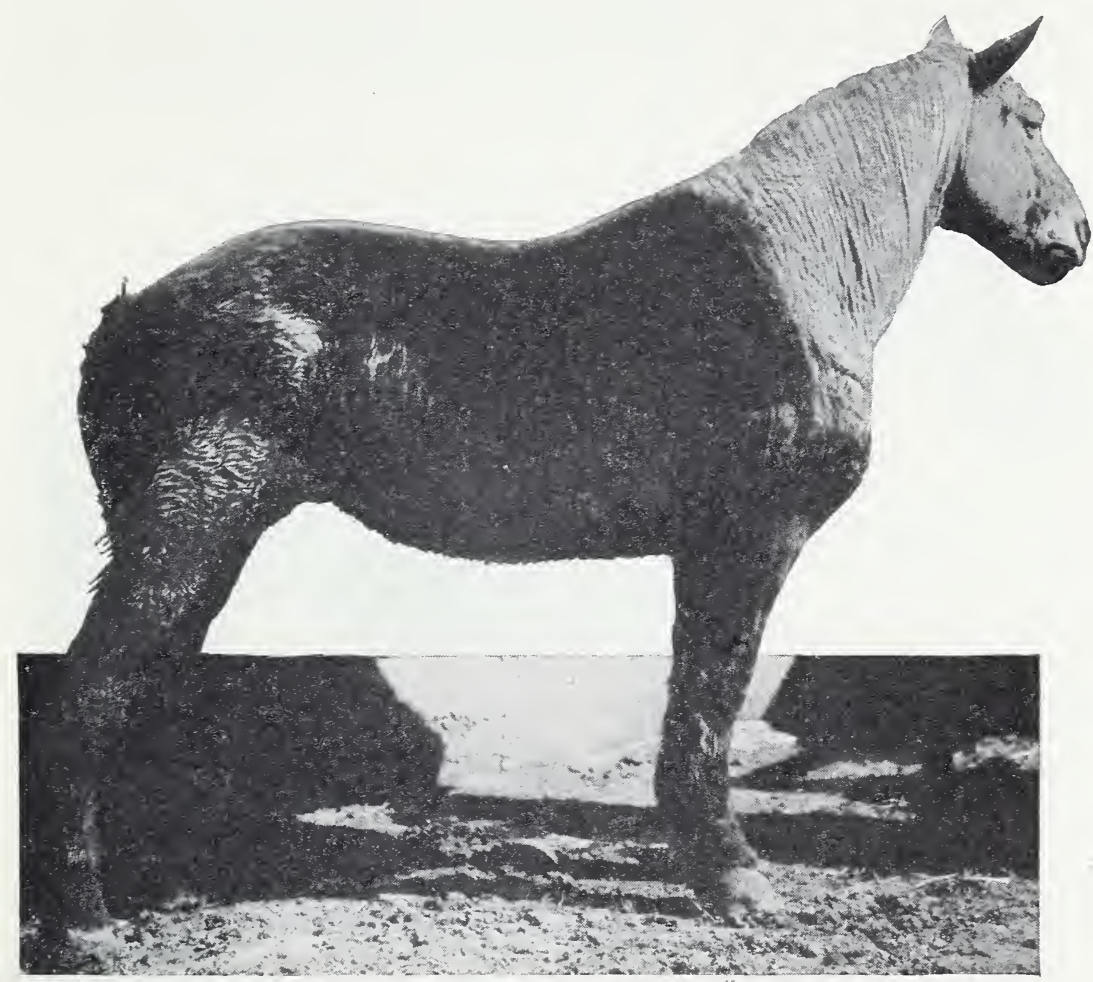

Figure 28.-Sarcoptic mange. Head, neck, and shoulders involved.

getting the dip or other insecticidal substances into the burrows and in contact with the mites. Practical experience has shown that the interval between treatments or dippings should be from 5 to 7 days.

Symptoms.- In the early stages of sarcoptic mange in horses the first risible lesions usually occur on the neck or shoulders or around the head, but the disease may start on the breast, flanks, sides, or other parts of the trunk. From these parts the disease spreads until the entire surface of the body may become involved.

The mites penetrate the upper layer of the skin, each female making a separate burrow or gallery, which usually extends to the sensitive tissues or "quick." The presence and activities of the mites on the sensitive tissues cause great irritation and itching, and the skin becomes inflamed and swollen, so that small nodules are formed over and around the burrows. As the disease develops vesicles are formed which break and discharge serum. As the serum dries, small scabs 
are formed, and the hair over the affected parts stands erect and some of it drops out. In some cases the affected areas of skin become dry and scurfy, and may have a leatherlike appearance (fig. 28.)

The mechanical injury to the skin resulting from rubbing and biting: causes large scabs to form, which adhere firmly to the underlying tissues. The large scabs often are broken by the morements of the animal, and blood or serum may stain the scabs a reddish yellow.

As the disease advances the skin becomes more or less bare in irregular-shaped, bald patches, and is greatly thickened and thrown into wrinkles or folds (fig. 29). In severe cases the horse loses flesh

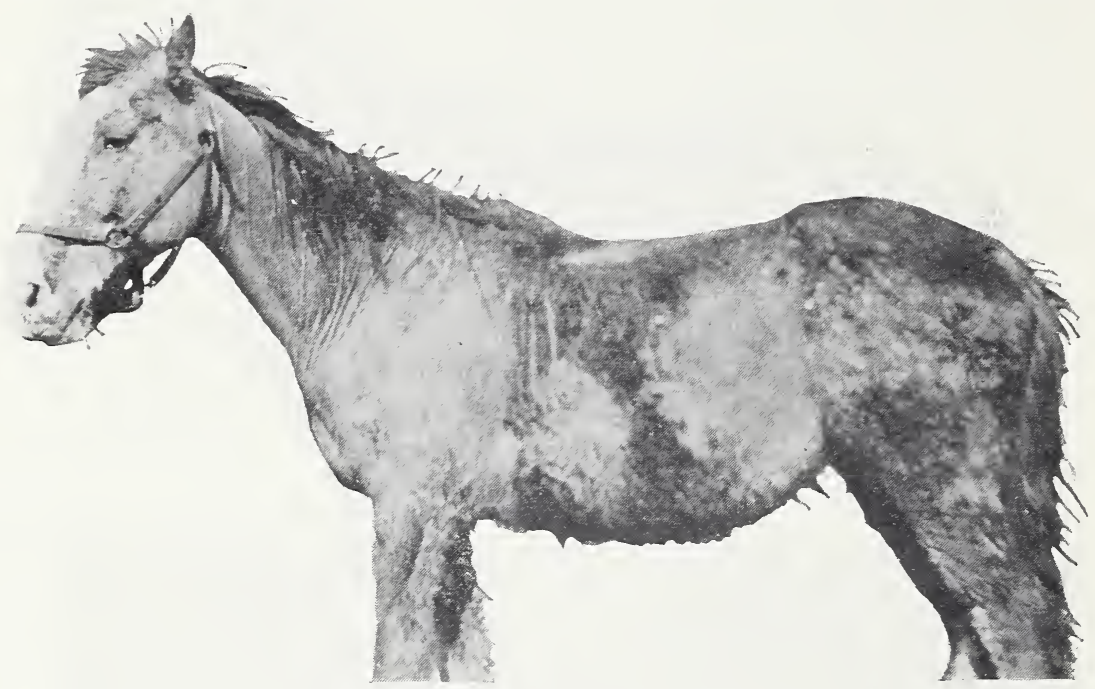

Figure 29.-A well-developed case of sarcoptic mange.

rapidly, becomes greatly weakened, and unless property treated may die.

Contagiousness.-Sarcoptic mange is transmissible from one species of animal to another, and also from animals to man. Ordinarily when one species of animal contracts the contagion from another species the mites live only a limited time on the new host. Sarcoptic mites of the sheep, hog, camel, dog, cat, and rabbit may live on hor'ses, and those of the horse, dog, and hog are known to be readily transmissible to man.

Sarcoptic mange of horses is contagious to all classes of horses and is usually transmitted by direct contact with infested animals. It may, however, be transmitted by other objects, such as currycombs, blankets, or harness, or in stables or other premises. It is important that mangy horses be isolated and all equipment kept separate until the disease is eradicated.

Apparently the disease spreads slowly during warm weather, especially among horses on pasture, but it makes rapid headway in horses closely confined or crowded together in small inclosures. Exposure to cold, inclement weather, insufficient feed, or feed of poor quality, or any other circumstances tending to lessen the vitality or functional activities of horses hastens the spread and derelopment of mange. 
When the mites are active under favorable conditions the lesions extend rapidly, and the entire body surface may become involved in about 6 weeks.

Although they do not propagate themselves except on the bodies of animals, the mites as well as their eggs may retain their vitality for a considerable time off the host animal. When exposed to sunlight in dry places the sarcoptic mites live only a few days, but in moist, protected places they may live 3 weeks or even longer. Although it is difficult to infect horses experimentally from infested premises, the possibility that the disease may be contracted from such sources should not be overlooked. It is good sanitary practice to clean and disinfect all stables and small inclosures which have been occupied by mangy horses, also all currycombs, brushes, blankets, and other objects used on such horses, before using them for clean animals. Cleaning and disinfecting for sarcoptic mange may be done in the same manner as for lice.

Treatment.-The common dips, such as lime-sulfur, nicotine, and coal-tar creosote, will kill sarcoptic mites if the dip can be brought into direct contact with the parasites. This method, however, requires thorough, frequent, and persistent applications. From four to six dippings, 5 to 7 days apart, in lime-sulfur or nicotine solution will usually effect a cure in ordinary cases, especially if all affected areas are soaked well with warm dip and scrubbed with a brush just prior to the first dipping. Affected animals should be held in the bath from 2 to 3 minutes.

Recent investigations have led to the discovery of new acaricides of particular promise for treating certain forms of mange. Among such substances are benzyl benzoate, tetraethylthiuram monosulfide, and benzene hexachloride. It would be wise, therefore, for individuals who are confronted with treating mange in horses to consult a veterinarian with regard to the possible applications of one of the newer substances.

Two or more applications, a week apart, of unprocessed crude petroleum will usually eradicate sarcoptic mange, if treatment is applied before the disease becomes chronic. Crude oils, however, often cause the hair to come out and may blister the skin. Crude oil is not a suitable dip for common use on horses, but it is of value in hand treatment for holding mange in check during the winter months when the temperature is too low for dipping.

Fumigation of many horses with sulfur dioxide has been recommended by some European investigators. The Bureau of Animal Industry has conducted some field tests with this method of treatment, but the equipment and methods of application so far devised are too complicated and expensive for general use except where large numbers of horses are assembled for treatment under the supervision of a veterinarian. This method of treatment has no advantage over dipping except that it can be used when the temperature is too low for dipping. In applying home treatment or fumigating for mange the medicament has a better chance of reaching the parasites if the hair over and around the lesions is first clipped and singed.

Cases of sarcoptic mange of long standing, which have been neglected and allowed to develop until the affected skin has become greatly thickened and leatherlike, are usually incurable by any ordinary 
method of treatment. In cases of suspected mange prompt and vigorous action should be taken, as the disease can be eradicated in the early stages at comparatively low cost.

\section{PSOROPTIC MANGE}

PSOROPTIC MANGE MITE

The mite (Psoroptes communis equi) which causes psoroptic mange lives on the surface of the skin and does not form burrows. Psoroptic

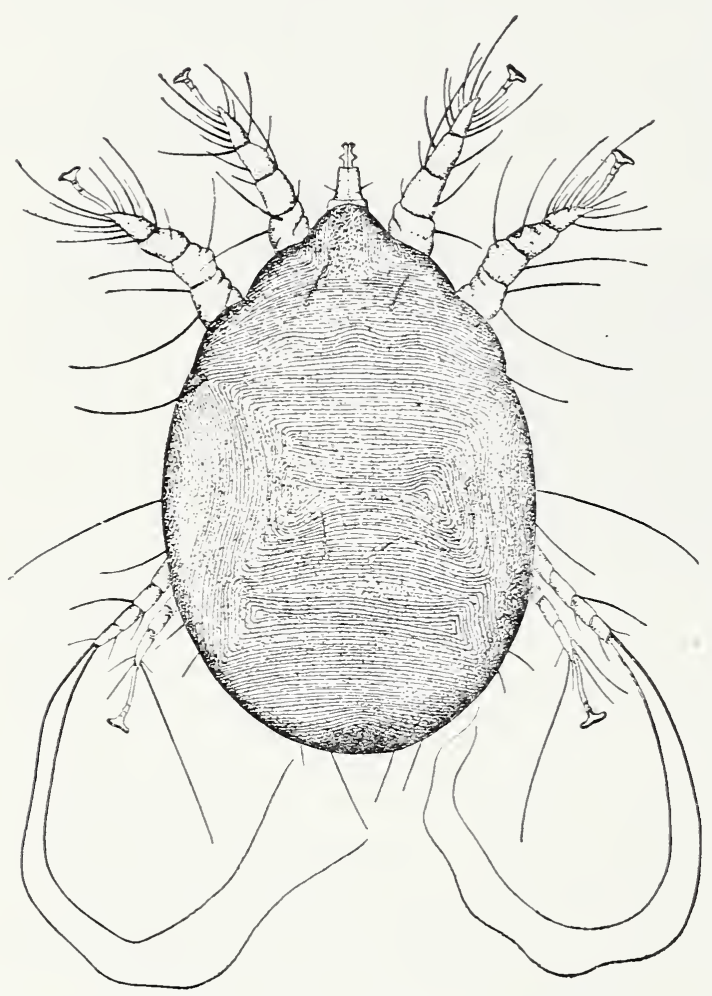

Figure 30.-Psoroptic mange mite. Female. (Magnified 100 times.) mites are slightly larger than sarcoptic mites, the mature female measuring about one-fortieth and the male about one-fiftieth of an inch in length (fig. 30). The entire life cycle is passed on the host animal. Each female may deposit from 15 to 24 ego's, which hatch in 3 to 4 days. The young mites reach maturity, mate, and the female deposits eggs in from 10 to 12 days.

Dipping, if properly done, kills all psoroptic mites, but cannot be depended on to destroy the egos. Some of the eggs may hatch after dipping, thus forming a new generation of mites. To effect eradication it is necessary to give a second dipping after hatching is completed and before the young mites reach maturity and begin laying eggs. It is evident that the interval between the first and second dippings should be from 10 to 12 days.

Symptoms.-Psoroptic mange may start on any part of the body covered thickly with hair, but the first lesions usually appear on the head under the foretop, on the top of the neck around the mane, or on the rump. From the starting point the disease spreads slowly over the body.

The mites prick the skin and probably introduce a poisonous secretion into the wound. A slight inflammation is caused, accompanied by an intense itching. In the early stages of the disease the lesions are not sufficiently prominent to attract attention, but the animals rub 
and bite themselves to relieve the intense itching, and these symptoms should always be investigated to learn the cause.

As the mites multiply, large numbers of small wounds are made in the skin, followed by the formation of papules, increased inflammation and itching, and the exudation of serum. The serum which oozes to the surface becomes mixed with foreign matter and microorganisms, and this mass soon hardens into yellowish or gray-colored scabs. The scabs are frequently stained with blood. In the early stages the hairs around the lesion may be glued together in a small clump and the nodule or scab may be about the size of a pea. As the mites constantly seek the healthy skin around the edges of the wound, the scab or lesion gradually increases in size.

Some of the mites migrate to other locations and start new lesions, which extend until they cover large areas. As the disease advances the skin becomes thickened, tumefied, and thrown into wrinkles or folds. Large areas become denuded of hair and covered with thick, adherent scabs. When the disease reaches this stage it is difficult to differentiate it from sarcoptic mange.

Itching is intense and irritation continues throughout the course of the disease. The skin becomes bruised and raw from the reckless rubbing against any available surface. The uniform thickening and hardening of the skin is characteristic of mange, but the most certain diagnosis consists in finding and identifying the mite which causes the disease. In the early stages of psoroptic mange the mites may usually be found in scrapings taken with a blunt-edged knife from around the edges of fresh lesions. In the advanced stages scrapings taken from the edges of scabs or from the bottoms of the folds of skin may contain mites.

In the early stages psoroptic mange may be distinguished from sarcoptic mange by the character of the lesions and the manner of spreading, but the most dependable diagnosis consists in finding the mite. For practical purposes where facilities for examination are limited the principal differences in form and structure of the two species of mites may be summarized thus: The sarcoptic mite is slightly smaller than the psoroptic mite, and the body of the former is more nearly round than oval (fig. 27). Adults of both species have four pairs of legs, those of the psoroptic mites being long, and all four pairs extend beyond the margin of the body (fig. 30). The sarcoptic mites have shorter legs, and the fourth or hind pair and usually the third pair do not extend beyond the margin of the body. The head of the common scab mite is tapering or cone-shaped and is longer than it is broad, whereas that of the psoroptic variety is bluntly rounded in front and is as broad as it is long.

It is advisable to examine several specimens in all cases, because under low-power magnifying glasses the females of the two species are more easily distinguished from one another than the males. On account of the burrowing habits of the sarcoptic mites, they are difficult to find, especially in the early stages of the disease. They are situated in burrows under conical papillae, and by scraping the infested area until the blood oozes from the tissue, the mites sometimes may be found in the scrapings. 
Contagiousness.-Each species of domesticated animal has its own peculiar variety of psoroptic mange, and the variety which lives on the horse, ass, or mule is not transmissible to other animals, with the possible exception of the camel. The disease is more highly contagious to all classes of horses than sarcoptic mange. The predisposing causes, manner of spreading, carriers of the mites, and precautions to be observed in isolating infected animals and cleaning and disinfecting premises are practically the same as for sarcoptic mange.

Treatment. - As the psoroptic mites live on the surface of the skin, they are more easily eradicated than the sarcoptic variety. The remedies recommended for sarcoptic mange are effective in eradicating this disease. Two dippings from 10 to 12 days apart may usually be depended on to cure ordinary cases. Four or more dippings may be necessary in chronic cases.

\section{CHORIOPTIC MANGE}

CHORIOPTIC MANGE MITE

Chorioptic or symbiotic scabies, commonly known as foot mange, is caused biv a mite (Chorioptes equi) which closely resembles the psoroptic mite. Chorioptic mites live on the surface of the skin and produce lesions similar to those of psoroptic mange.

The lesions of chorioptic mange are usually confined to the lower part of the limbs around the foot and fetlock. Occasionally the mites spread over the legs above the hocks, and may reach even the thighs and abdomen, but usually the disease remains localized around the feet.

Infested animals paw and kick and rub the pastern with the opposite foot and often try to bite the affected parts. Some of the hair comes out and the skin has the thickened and hardened condition characteristic of scabies.

The remedies recommended for sarcoptic mange are effective in eradicating foot mange. The affected areas should be well soaked in warm lime-sulfur dip, and the treatment repeated every 10 days until a cure is effected. Driving the horses through a shallow wading tank filled with dip is a quick and effective method of treatment for foot mange.

\section{TICKS}

There are many different kinds of ticks which may attack horses, but since the habits and life cycles of the different species vary greatly discussion in this circular is necessarily limited to general information, except for the ear tick, which is discussed more fully.

When only a few ticks are found on horses they may be removed by hand or covered with crude petroleum, cylinder oil, kerosene, or other oil, which usually causes them to detach and drop to the ground. In remoring ticks by hand the writer has observed that they may sometimes be detached without leaving the head embedded in the skin by twisting them around as they are pulled loose.

In the southern and western parts of the United States it is not uncommon for horses to become grossly infested with ticks. In some sections the infestation may occur only infrequently; in others it may 

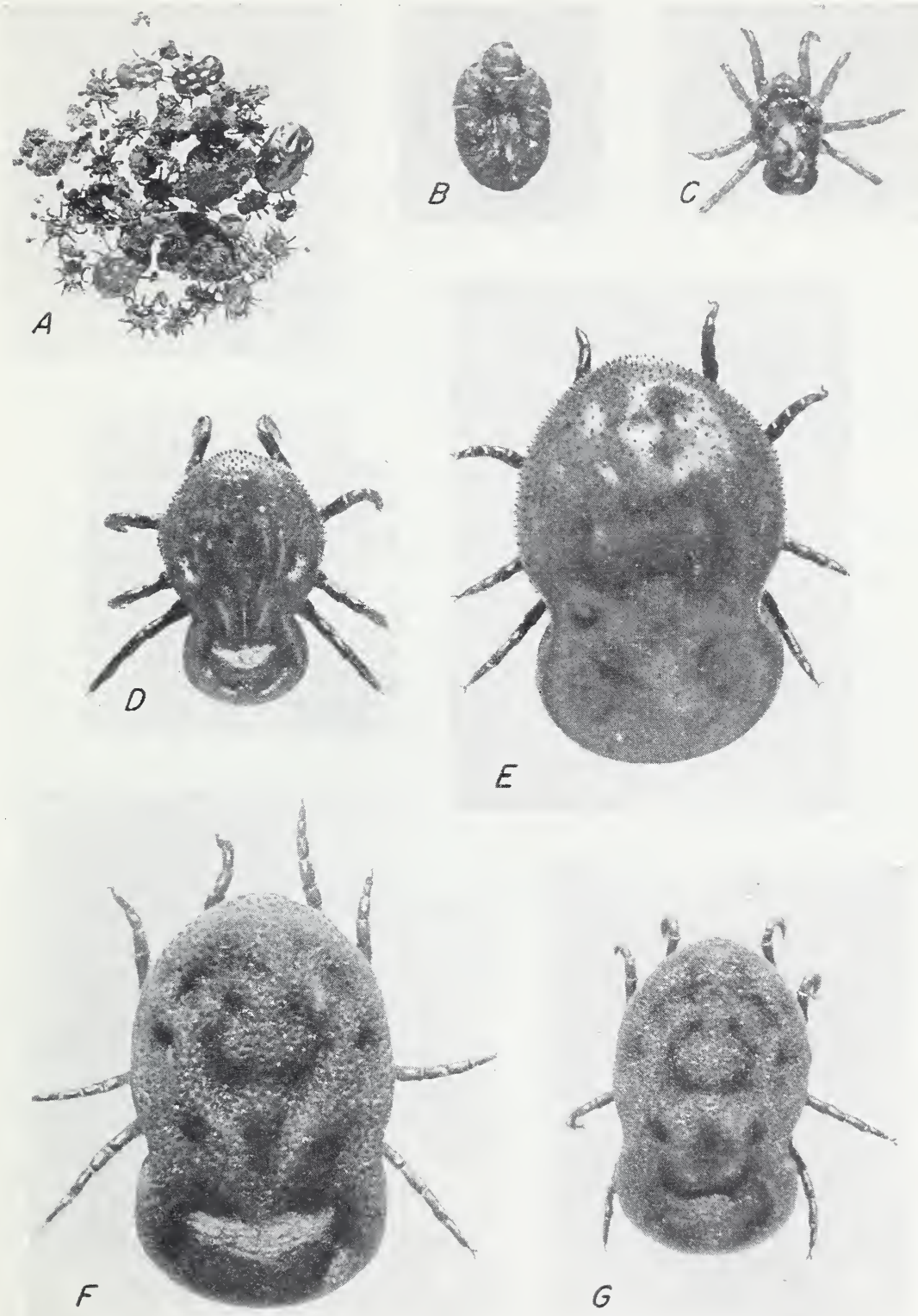

Figure 31.- $A$, Ear ticks and debris from ear of animal (about natural size); $B$, engorged larva (magnified 5 times); $C$, young tick (magnified 5 times); $D$, partially engorged young tick (magnified 5 times); $E$, fully engorged young tick (magnified 5 times); $F$, adult female (magnified 5 times); $G$, adult male (magnified 5 times). 
occur more or less regularly each year. In the region infested with cattle-fever ticks where eradication work is in progress, tick-infested horses are dipped in arsenical solution to kill the parasites.

In any locality where the horses become infested with ticks and the infestation is extensive the State livestock sanitary authorities should

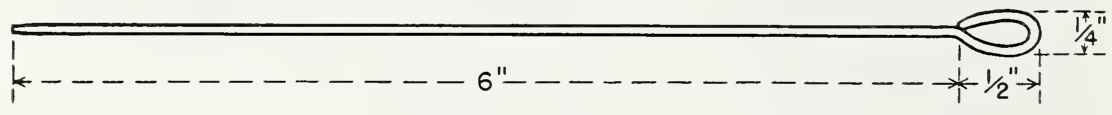

Figure 32.-Ear probe made of baling wire.

be notified in order that the ticks may be identified and proper measures taken for control. Control or eradication methods to be successful must be based on a knowledge of the life history and habits of the tick involved.

\section{SPINOSE EAR TICK ${ }^{5}$}

Nature and habits.-The spinose ear tick (Otobius mégnini) is prevalent on horses in the Southwest and causes serious damage to the livestock industry. Spinose ear ticks (fig. 31) enter the ears of animals as small, six-legged seed ticks and attach themselves in the external canal well below the hair line, where in a week or two they become engorged larvae. The engorged larvae molt to form nymphs or young ticks having eight legs. The young ticks remain in the ears from 1 to 7 months, or until fully grown and engorged, when they drop to the ground, crawl up into dry, protected places above the ground, and again molt. The skin of the nymph is covered with spines, but that of the mature tick is smooth. So far as is known the adult tick does not attach itself to animals nor does it take food. Mating and egg laying take place off the animal, and when egg laying is completed the female dies. The eggs may hatch as early as 10 days after they are laid. Shortly after hatching the seed ticks are ready to attach themselves to any suitable host. They may live as long as 3 months if no host is found.

Symptoms.-When animals are grossly infested and the ear canals packed full of ticks the parasites are visible on superficial examination, but when the degree of infestation is light or moderate the ticks may be overlooked. They usually attach themselves in the deep folds of the ear or crawl into the ear canal and follow it inward, sometimes as far as the eardrum. As the ticks increase in size and others enter, they and the excretions, with the wax from the ear, accumulate in masses or plugs sufficient in some cases to close up the ear passages completely. These conditions give rise to various symptoms. The infested animal usually shakes it head and repeatedly turns it from side to side, meanwhile inverting, or turning down, first one ear and then the other. When irritation and itching are more intense on one side the animal often turns it head so that the more seriously affected ear is held downward. There is a tendency to rub and scratch the ears, and young animals often run as though endeavoring to relieve the nervous tension.

5 For more complete information, see Farmers' Bulletin 980 entitled "The Spinose Ear Tick" revised August 1947, by H. E. Kemper of the U. S. Bureau of Animal Industry. 
In all cases where ear-tick infestation is suspected the animals should be examined, and if no ticks are visible the ears should be probed. A convenient and effective instrument for probing the ears, removing ticks from the ear canals, and breaking down masses of ear wax and ticks may be made from a piece of ordinary bailing wire, as shown in figure 32 , the loop end being used for dislodging the ticks.

Treatment. - A widely used remedy for ear ticks consists of a mixture of two parts by volume of ordinary pine tar and one part by volume of cottonseed oil. In mixing the ingredients add the cottonseed oil to the pine tar and stir until a uniformly smooth mixture is obtained. When necessary the ingredients should be warmed before mixing, so that they will mix readily and flow freely. The mixture remains uniform without separation or deterioration, and may safely be used on any species of domesticated animal. About one-half ounce of the material should be put into each ear, and the ear should be held upright for a few seconds and manipulated to force the material into the deeper parts.

Other substances have been used, sometimes with good results. Chloroform, for example, either undiluted or mixed with a bland oil, is effective, but substances of this nature evaporate rapidly and therefore afford no protection against reinfestation.

The use of pyridine in a nondrying adhesive smear has been recently recommended. The formulation used is known as "Stock 1029." This formulation has been tested chiefly in cattle, although there can be little doubt that it possesses a useful application to horses as well.

Another comparatively new remedy possessing effective action against ear ticks, although lacking extensive trials in horses, contains benzene hexachloride as the active ingredient. Under experimental conditions, preparations consisting of 5 percent of this insecticide in pure pine oil, or in emulsifiable petroleum oil, have offered promise of being superior to any of the aforementioned remedies. On account of the variable content of active insecticidal material in benzene hexachloride, it is probable that the best formulations for the purpose described will be found in preparations that are marketed or recommended specifically for the destruction of ear ticks when the treatment shall have progressed beyond the experimental stage.

Complete eradication of spinose ear ticks is difficult on account of the habits of the ticks, their great vitality, and the wide range of animals which they infest. Moreover, most horses oppose the insertion of anything into their ears. Some form of restraint is almost always necessary if treatment is to be given effectively. Farm horses can usually be controlled with a twitch or by other common methods of restraint, but special equipment is usually necessary for treating range animals. An ordinary crowding chute not more than 3 or 4 feet wide is suitable for treating most horses for ear ticks.

The only known effective method of applying treatment for the destruction or eradication of ear ticks is to insert the remedy into the ear passages by hand. This can be done by means of ordinary metal or hard rubber syringes, cut-down oilers, small paint brushes, or properly equipped knapsack sprayers. Mixtures should flow freely and be applied in such manner as to insure complete coverage of the deep convolutions and the inner surface of the outer ear. The material should not be permitted to overflow, since some of the substances, 
like the pine tar-cottonseed oil mixture. mar cause irritation or blistering if thes run down orer the head and face where ther are exposed to the direct rars of the sun.

When the ear passages contain masses of hard wax and ticks, it is desirable to clean out the material before treatment is applied. The treatments recommended can be depended upon to kill all ticks in the ears and to prerent reinfestation for a month or more. although the onls rule regarding the frequener of treatment is to apply the remedies as often as necessart to keep the ears free of ticks.

Finallr, it should be remembered that the eggs of ear ticks are not deposited or hatched in the ears of animals. and that a new crop of seed ticks mar find lodgment at ant time on animals kept in infested places.

\section{Treating Horses for External Parasites}

The three commonly used methods of treating horses. mules, and asses for external parasites are (1) hand applications. (2) spraring. and (3) dipping. A fourth method. not in common use but recommended br some European inrestigators, is fumigation with sulfur dioxide.

\section{HAND APPIICATIONS}

Infested animals may hare parasites on any or all parts of the bodr surface, and to effect complete eradication usually it is necessart to cover the entire surface of the skin with the medicament. On account of the difficulty of applying treatment by hand orer the entire bodr surface, hand applications are recommended onlr as a temporary measure for holding parasites in check until the animals can be dipped or sprared.

\section{SPRAIING}

Common parasites on or in the skin can be eradicated br proper spraring. but the method commonls practiced is not economical. It is difficult to wet the hair coat of an animal with a sprar. and much of the liquid runs off and is wasted. Spraring is not effectire unless all parts of the skin and hair are well soaked.

An ordinary orchard-spraring outfit or a common hand pump equipped with hose and spras nozzle mas be utilized for spraring animals.

\section{FUMIGATING}

Fumigation consists in exposing animals to the fumes of burning sulfur sulfur dioxide) or some other gas. The animals to be fumigated are placed in a castight chamber with the head projecting through an opening and the nose and eres protected from the gas (fig. 26). This method is often recommended for treating animals for external parasites.

Investigations conducted by the Bureau of Animal Industry hare shown that the present known methods of fumigating animals are not suitable for general use. The minimum effective concentration of sulfur dioxide for mange apparently is about $t$ percent and for lice about 1 percent. Under ordinars conditions the concentration or 
percentage of gas in the air cannot be raised to more than about 1.5 or 2 percent by burning sulfur in the gas chamber unless special apparatus is installed. Sulfur dioxide compressed to a liquid and stored in steel cylinders is available on the market. By using the compressed gas any desired concentration in the chamber within certain limits may be obtained. In winter, when the temperature is too low for dipping, fumigation is feasible if a large number of horses are to be treated and competent men are available to supervise the work. This method apparently has no other distinct advantage over dipping.

\section{DIPPING}

Dipping is the most effective known method of applying treatment for common external parasites. Dipping plants are so arranged that the animals are immersed in liquid deep enough to swim in, and the entire body surface is well soaked. For dipping horses the dip in the vat should be kept at a depth of 70 to 80 inches, or sufficient to immerse completely the tallest animal to be dipped. Horses will carry out and retain from 2 to 4 quarts of dip each, and the depth of the liquid in the vat will be lowered accordingly. The total estimated quantity of dip which the animals carry out plus that required to charge the vat should equal the total quantity required, provided none is lost by leakage or otherwise wasted.

The capacity of the vat is usually obtained by multiplying, in terms of inches, the average length by the average width, then the product by the depth. This gives approximately the number of cubic inches of space to be filled with dip. Divide this by 231 (the number of cubic inches in a gallon), and the result will be the number of gallons of dip needed to charge the vat.

To obtain the average length, add the length at the bottom to the length at the dip line and divide by 2 . The average width is obtained in the same manner. The depth should be taken at the center of the vat and from the bottom to the dip line only, and not to the top. All measurements should be made only of the space to be filled with dip, and not above the dip line. The capacities of the various tanks are obtained by like process.

Before dipping, the contents of the vat should be well stirred, in order that the dip may be of uniform strength and temperature throughout. The pens, chutes, vat, etc., should be examined for projecting nails or any object that might puncture or wound the horses, as the dip may injure those having fresh wounds.

In dipping wild range horses it is necessary to have a gate or bar in the chute to prevent the animals from piling up in the vat. Horses should be watered and fed from 2 to 4 hour's before dipping, and if heated by driving they should be allowed to cool off before entering the vat.

The head of each animal should be completely submerged for an instant at least once while in the vat. The head should not be held under, but quickly ducked with a dipping fork and released. Two duckings of the head are advisable, especially if the animals are affected with scabies. Care should be taken to see that the inner surface of the ear is well soaked. 
In dipping for lice it is not necessary to hold horses in the vat, but if they have scabies they should be held in the vat 2 or 3 minutes. After leaving the vat the animals should be held in the draining pens until all surplus dip has drained off their bodies. Dipping should be finished for the day early enough to dry the animals before sunset.

Before approving a dip for use in official dipping one of the requirements of the Bureau of Animal Industry is that there shall be a practical field test for such dip. Of the various classes of dips used on horses, three only are on the approved list-arsenicals, limesulfur, and nicotine. Of these the two most commonly used are the lime-sulfur dip for mange and the arsenical dip for lice and ticks.

\section{ARSENICAL DIP}

Arsenical dip, when properly used, eradicates biting and sucking lice, but it is not an effective remedy for mange. Prepared arsenical dips have been placed on the market, but those which are permitted by the Government for use in dipping cattle for southern fever ticks are suitable for use in dipping horses, mules, and asses for lice. The instructions on the label of the container should be followed in diluting and using ready-prepared dips. The arsenical dip is not usually warmed or heated in the vat.

It should be remembered that arsenical dip is a poison, and precaution should be taken to prevent injury to man or animal. When it is handled and used with proper care it is a safe and effective remedy. Care should be taken not to get the clothing wet with the dip, and the hands should be washed frequently to prevent possible absorption of arsenic.

Freshly treated animals should be held in the draining pens or other suitable place until all surplus dip has drained off. If allowed to drain where pools of dip collect from which the animals may drink, or if the pasture or feed becomes soiled with arsenical dip, losses are liable to occur.

If home-made arsenical dip is preferred to the proprietary brands, see United States Department of Agriculture Farmers' Bulletin 1057 for full instructions for making it.

\section{LIME-SULFUR DIP}

Proprietary brands of liquid lime-sulfur may be purchased, and many of them are equal to or even better than the home-made product. Manufacturers have also placed on the market a product commonly known as dry lime-sulfur, made by evaporating, in vacuo or in the presence of an inert gas, concentrated lime-sulfur solution to which a small amount of cane sugar has been added to act as a stabilizing agent. Dry lime-sulfur is readily soluble in hot water, and it is being extensively used as a dip for animals and as an insecticide for plants. Prepared dips should be diluted and used in accordance with instructions printed on the label of the container. Lime-sulfur dips are efficacious and dependable remedies for mange, but they are not effective against lice and ticks.

Home-made lime-sulfur dip is made in the proportion of 12 pounds of unslaked lime (or 16 pounds of commercial hydrated lime) and 24 
pounds of flowers of sulfur to 100 gallons of water. The lime and sulfur should be weighed and the water measured; do not trust to guess work. Slake the lime in a shallow, water-tight box or tank and add water enough to form a thin paste. Sift the sulfur into the paste and mix well with a broad hoe until a mixture of about the consistence of mortar is formed, adding water as required. Put the mixture into 30 gallons of boiling water, adding it slowly so as not to interrupt the boiling, and boil until the sulfur disappears from the surface. The boiling should be continued for from $1 \frac{1}{2}$ to 2 hours without cessation, and the mixture stirred to prevent settling and caking on the bottom. When the sulfur has disappeared from the surface and the mixure is of a chocolate of dark-amber color, the boiling should be discontinued.

The contents of the boiling tank should be drawn off or dipped out and placed in the settling tank and allowed to stand until all solids have settled to the bottom and the liquid is clear. An ordinary watertight barrel will serve very well for a settling tank at a small vat. A settling tank of any kind should have an outlet at least 4 inches from the bottom in order that the clear liquid may be drawn off without becoming mixed with any of the sediment.

When the sediment has fully settled draw off the liquid into the dipping rat and add warm water to make a total of 100 gallons of dip. When mixed and cooked as specified above the concentrate is $3 \frac{1}{3}$ times the strength required for the dip in the vat, so that to every 30 gallons of such concentrate 70 gallons of warm water should be added to make a dip of the required strength.

In preparing lime-sulfur dip in large quantities several hundred gallons of concentrate are often made at one time in a single large cooking tank. The quantity made at one boiling is limited only by the facilities at hand. If the boiling tank is of sufficient capacity, a large enough quantity of dip should be cooked at one time to dip the herd. The quantity of mixture in the cooking tank may be raried at will, but the proportions of the various ingredients should not be altered.

\section{NICOTINE DIPS}

The nicotine dips sold under rarious trade names are commonly used for dipping animals and spraying plants for insect pests. They are efficacious remedies for horse lice and mange when diluted with water so that the solution contains not less than five one-hundredths of 1 percent nicotine. If used much stronger, they are liable to injure horses, especially if the animals are dipped while they are warm from exercise or hot weather.

Nicotine dips are generally used warm, but should not be heated above $110^{\circ} \mathrm{F}$. The temperature of the bath should be maintained at $90^{\circ}$ to $95^{\circ}$. Sulfur is sometimes added to nicotine dips in the proportion of 16 pounds of flowers of sulfur to 100 gallons of diluted dip. The addition of sulfur increases the effectiveness of the dip for mange and extends the period of protection against reinfestation. These dips should be diluted and used in accordance with instructions printed on the label of the container. Do not use a nicotine dip the strength of which is not given on the label. 


\section{COAL-TAR CREOSOTE DIPS}

The coal-tar creosote dips, commonly known as coal-tar dips. are sold under mant trade names. Ther are made from coal-tar derivatives, and the principal ingredient is creosote oil. which is made miscible with water br means of soap. When diluted with soft water ther are efficacious in eradicating lice, but ther are not dependable remedies for sarcoptic mange.

Before using a coal-tar creosote dip in hard or alkaline water. dilute a small. measured quantitr of the dip with the water in the proportion to be used in dipping and place in a clean glass container. If after standing for 1 hour, an oily layer or mass of globules appears either at the top or at the bottom of the liquid. the dip should not be used with that kind of water, as it is liable to injure the animals. Injury mar occur eren when there is no apparent separation in the dip so tested.

The coal-tar creosote dips mar be used cold or warm. but the temperature of the bath should not exceed $95^{\circ} \mathrm{F}$. Ther should be diluted and used in accordance with the instructions printed on the label of the container.

\section{OII DIPS}

Ferosene. crude petroleum. crank-case drainage from gasoline motors and other oils and greases are commonly used in treating horses for extemal parasites. When properly used thet will control mange and lice. but ther often injure horses br blistering the skin and causing the hair to fall out. Oil dips are not recommended for common use in dipping horses.

Cottonseed oil and kerosene. equal parts. or kerosene one-half pint to 1 pound of lard or crude petroleum is often applied br hand to hold mange and lice in check when the weather is too cold for dipping.

\section{DIPPING VATS}

In those sections of the Lnited States where there are a large number of horses to be dipped cattle-dipping rats usuallr are arailable. and ther can be utilized for dipping horses. Plans of cattle-dipping rats suitable for dipping horses are given in Farmers Bulletins 1017 and 1057 .

The so-called cage rats are sometimes used for dipping horses. In these rats the animal is placed in a morable cage and lowered into the bath br means of a windlass or other mechanical apparatus. The operations are much slower than in the longitudinal rat.

Portable. galranized-metal rats mar be purchased. and ther are suitable for dipping a small number of animals. After digging a trench and setting the rat so that the top is flush with the surface of the ground. a chute and slide board should be prorided as a means of getting the horses into the rat. 
$x=$

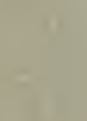

$+1$
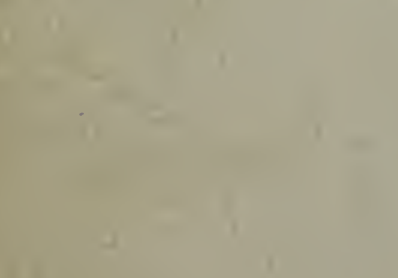

(1)
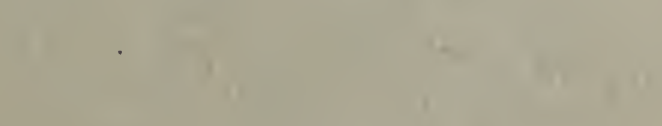
